ANA BÁRBARA TEIXEIRA ALVES WAGNER

\author{
EFEITO DA ASSOCIAÇÃO ENTRE HIPERTENSÃO \\ ARTERIAL E DIABETES NA EXPRESSÃO DO \\ Slc2a4/GLUT4 NO MÚSCULO ESQUELÉTICO, \\ PROVÁVEL PARTICIPAÇÃO DO SISTEMA NERVOSO \\ AUTÔNOMO SIMPÁTICO $\beta$-ADRENÉRGICO
}

Tese apresentada ao Programa de PósGraduação em Fisiologia Humana do Instituto de Ciências Biomédicas da Universidade de São Paulo, para obtenção do Título de Doutor em Ciências 


\title{
EFEITO DA ASSOCIAÇÃO ENTRE HIPERTENSÃO ARTERIAL E DIABETES NA EXPRESSÃO DO Slc2a4/GLUT4 NO MÚSCULO ESQUELÉTICO, PROVÁVEL PARTICIPAÇÃO DO SISTEMA NERVOSO AUTÔNOMO SIMPÁTICO $\beta$-ADRENÉRGICO
}

\author{
Tese apresentada ao Programa de Pós- \\ Graduação em Fisiologia Humana do \\ Instituto de Ciências Biomédicas da \\ Universidade de São Paulo, para obtenção \\ do Título de Doutor em Ciências \\ Área de Concentração: Fisiologia Humana \\ Orientador: Prof. Dr. Ubiratan Fabres \\ Machado \\ Versão corrigida. A versão original \\ eletrônica encontra-se disponível tanto na \\ Biblioteca do ICB quanto na Biblioteca \\ Digital de Teses e Dissertações da USP \\ (BDTD)
}




\section{DADOS DE CATALOGAÇÃO NA PUBLICAÇÃO (CIP)}

Serviço de Biblioteca e Informação Biomédica do

Instituto de Ciências Biomédicas da Universidade de São Paulo

reprodução não autorizada pelo autor

Wagner, Ana Bárbara Teixeira Alves.

Efeito da associação entre hipertensão arterial e diabetes na expressão do Sic2a4/GLUT4 no músculo esquelético, provável participação do sistema nervoso autônomo simpático $\beta$-adrenérgico / Ana Bárbara Teixeira Alves Wagner. -- São Paulo, 2012.

Orientador: Prof. Dr. Ubiratan Fabres Machado.

Tese (Doutorado) - Universidade de São Paulo. Instituto de Ciências Biomédicas. Departamento de Fisiologia e Biofisica. Área de concentração: Fisiologia Humana. Linha de pesquisa: Estudos de fisiologia endócrina.

Versão do título para o inglês: The effect of hypertension and diabetes association on Sic2a4/GLUT4 expression, possible $\beta$ adrenergic sympathectic nervous system participation.

1. Diabetes mellitus 2. Neuropatias diabéticas 3 . Sistema nervoso simpático 4. Receptores adrenérgicos I. Machado, Prof. Dr. Ubiratan Fabres II. Universidade de São Paulo. Instituto de Ciências Biomédicas. Programa de Pós-Graduação em Fisiologia Humana III. Título. 
Candidato(a):

Título da Tese:
Ana Bárbara Teixeira Alves Wagner.

Efeito da associação entre hipertensão arterial e diabetes na expressão do SIc2a4/GLUT4 no músculo esquelético, provável participação do sistema nervoso autônomo simpático $\beta$-adrenérgico.

Prof. Dr. Ubiratan Fabres Machado.

Orientador(a):

A Comissão Julgadora dos trabalhos de Defesa da Tese de Doutorado, em sessão pública realizada a .l. ...................., considerou

( ) Aprovado(a)

( ) Reprovado(a)

Examinador(a): Assinatura:

Nome:

Instituição:

Examinador(a): Assinatura:

Nome:

Instituição:

Examinador(a): Assinatura:

Nome:

Instituição:

Examinador(a): Assinatura:

Nome:

Instituição:

Presidente: Assinatura:

Nome:

Instituição: 


\section{Certificado}

Certificamos que o protocolo registrado sob $n^{\circ} \mathbf{0 1 5}$ nas fls. $\mathbf{5 5}$ do livro 02 para uso de animais em experimentação, sob a responsabilidade de Ubiratan Fabres Machado, Coordenador(a) da Linha de pesquisa "Iffeito do sistema nervoso autônomo simpático beta-adrenérgico sobre a expressão do gene do GLUT4 em ratos espotaneamente hipertensos (SHR) diabéticos" do qual participou(aram) o(s) alunos Ana Bárbara Teixeira Alves está de acordo com os Princípios Éticos de Experimentação Animal adotado pelo Colégio Brasileiro de Experimentação Animal (COBEA) e foi aprovado pela COMISSÃO DE ÉTICA EM EXPERTMENTAÇĀO ANIMAL (CEEA) em 29.04.08, com validade de 3 anos.

São Paulo, 29 de abril de 2008.

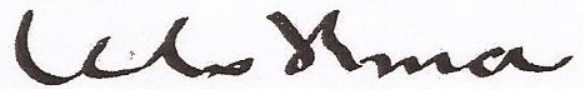

Prof. Dr. WOTHAN TAVARES DE LIMA Coordenador CEEA - ICB/USP

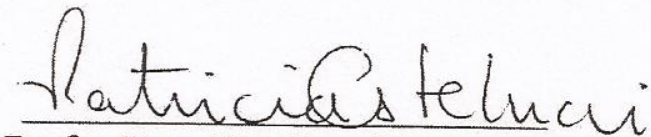

Profa. Dra. PATRICIA CASTELUCCI

Secretária CEEA - ICB/USP 


\section{REF.: Protocolo n015/08.}

"Efeito do sistema nervoso autônomo simpático beta-adrenérgico sobre a expressão do gene do GLUT4 em ratos espontaneamente hipertensos (SHR) diabéticos"

Prezado Professor,

$$
\text { Informo que a sua licença para uso de animais em }
$$

experimentação, constante no protocolo em epígrafe, foi prorrogada até 29.04.2014.

$$
\text { Reitero que havendo alteração de metodologia e inserção de }
$$
novos alunos ao projeto de pesquisa vinculado à referida licença a CEUA/ICB deverá ser informada.

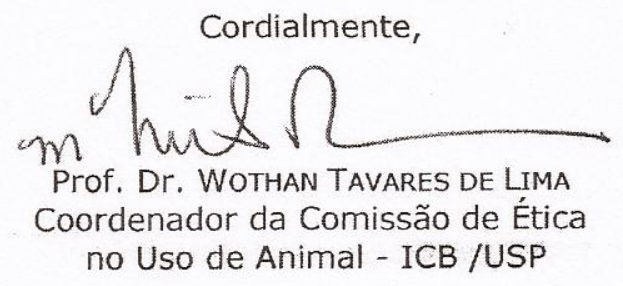

IImo. Sr.

Prof Dr. Ubiratan Fabres Machado

Departamento de Fisiologia e Biofisica

Instituto de Ciências Biomédicas - USP 


\section{AGRADECIMENTOS}

Agradeço a todas as pessoas que me ajudaram e tornaram possível o término dessa tese, em especial:

Ao Prof Dr Ubiratan Machado;

Às minhas amigas Raquel, Rosana e Daniella;

Aos meus colegas Maristela, Helayne, Aline, Patrícia, Milano, Daniela;

Aos professors do ICB, em especial à profa Luciana Rossoni;

Ao José Maria e Paloma;

Aos funcionários da biblioteca;

Ao Mathias Wagner;

Aos meus pais, sogros, irmãos e cunhados;

À Universidade de São Paulo;

À Fapesp pelo auxílio financeiro (2007-2009, 2011-2012);

À profa Dra Laurie Goodyear e a todos os meus colegas do laboratório de Joslin Diabetes Center pelos ensinamentos;

À Capes pelo apoio financeiro do doutorado sanduiche realizado em Joslin Diabetes Center, Harvard Medical School (2009-2011). 
Para meus amigos e colegas cientistas:
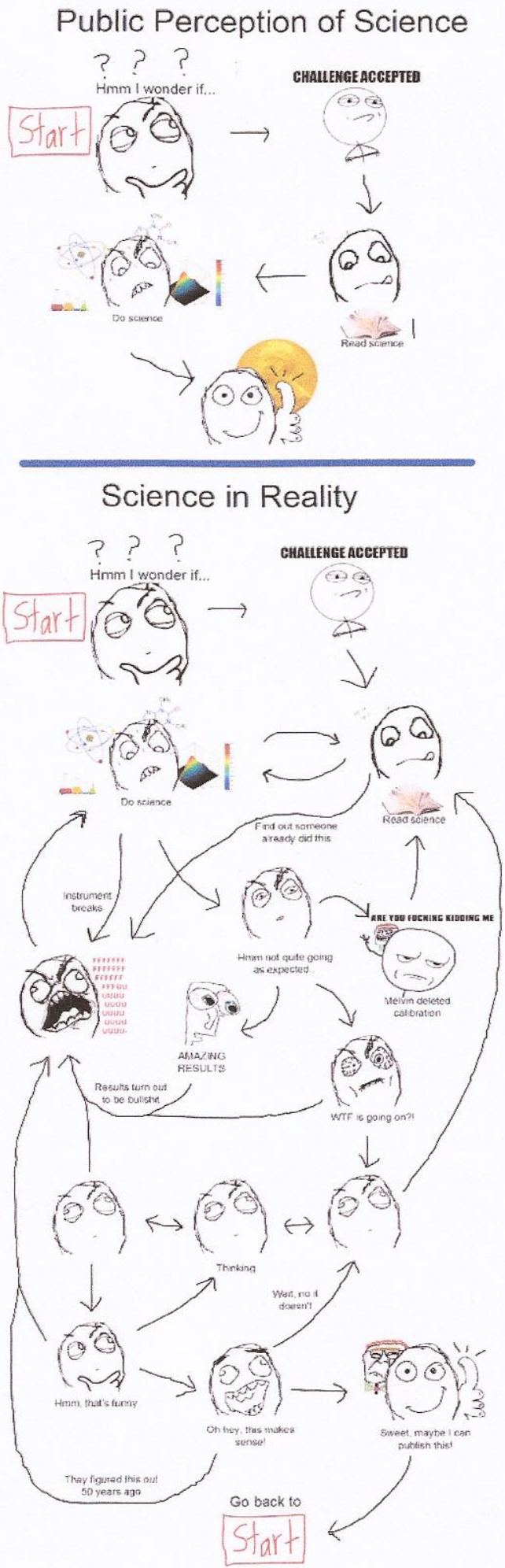

(http://electroncafe.wordpress.com/2011/05/04/scientific-process-rage/) 
Your work is going to fill a large part of your life, and the only way to be truly satisfied is to do what you believe is great work.

And the only way to do great work is to love what you do.

If you haven't found it yet, keep looking. Don't settle.

As with all matters of the heart, you'll know when you find it. And, like any great relationship, it just gets better and better as the years roll on.

So keep looking until you find it. Don't settle.

(Steve Jobs) 


\section{RESUMO}

ALVES-WAGNER A. B. T. Efeito da associação entre hipertensão arterial e diabetes na expressão do Slc2a4/GLUT4 no músculo esquelético, provável participação do sistema nervoso autônomo simpático $\beta$-adrenérgico. 2012. 68 p. Tese (Doutorado em Fisiologia Humana) Instituto de Ciências Biomédicas, Universidade de São Paulo, São Paulo, 2012.

A proteína GLUT4, codificada pelo gene Slc2a4 (Solute carrier 2a4) é um transportador de glicose responsivo à insulina que está localizado principalmente em células musculares e adipócitos. Alterações na expressão do GLUT4 correlacionam-se de maneira direta com o aumento ou diminuição na homeostase glicêmica. Já foi demonstrado que o sistema $\beta$ adrenérgico modula a expressão de GLUT4 no jejum, porém pouco se sabe no diabetes. O diabetes pode levar o desenvolvimento de neuropatia, com isso nós hipotetizamos que alterações na atividade $\beta$-adrenérgica possa modular a regulação do Slc2a4/GLUT4 induzida pelo diabetes. Neste trabalho investigamos como a alta atividade simpática atua na expressão do Slc2a4/GLUT4 em músculo esquelético de ratos Wistar diabéticos e ratos espontâneamente hipertensos (SHR) diabéticos, os quais apresentam alta atividade simpática no músculo esquelético. Primeiramente utilizamos ratos Wistar, Wistar-Kyoto e SHR diabéticos por 1 mês para analisarmos a expressão do Slc2a4 e do GLUT4 em músculo oxidativo (sóleo) e glicolítico (EDL), comparando com os respectivos animais não diabéticos. O diabetes reduziu a expressão do Slc2a4 e GLUT4 em animais Wistar, como o esperado. Porém isso não foi observado em Wistar-Kyoto e SHR, com isso decidimos usar o Wistar como controle do SHR. Ratos Wistar diabéticos (W-normotenso) e ratos espontaneamente hipertensos - SHR diabéticos (Shipertenso) foram tratados com salina (S), insulina (I), propranolol (P) e propranolol+insulina (PI). Os tratamentos foram feitos por uma semana, iniciando-se um mês após a indução do diabetes. Como esperado, o tratamento com insulina reduziu a glicemia, glicosúria e volume urinário, e aumentou o peso nos animais normotensos e hipertensos. $O$ tratamento com propranolol, que reduziu a pressão caudal dos animais hipertensos, não alterou os parâmetros metabólicos analisados. A expressão do Slc2a4 no sóleo foi aumentada pela insulina, nos normotensos e hipertensos, e reduzida pelo propranolol, somente nos normotensos. No EDL, os resultados foram, no geral, inversos, com a insulina reduzindo e o propranolol aumentando a expressão do mRNA. A associação do propranolol+insulina mostrou que em sóleo o efeito da insulina foi preponderante, entretanto, no EDL o propranolol atenuou o efeito da insulina. Vale 
ressaltar que, independente dos tratamentos, a expressão do Slc2a4 se mostrou sempre mais alta nos animais hipertensos (vs. respectivos animais normotensos), em ambos os músculos estudados. A regulação da expressão da proteína acompanhou parcialmente a regulação do mRNA, mostrando alterações pós-transcricionais em alguns casos, e alteração por Tnfa, em outros casos. No sóleo, os animais hipertensos apresentaram maior quantidade de receptores $\beta_{2}$ adrenérgicos. Em síntese, conclui-se que nos músculos esqueléticos a alta atividade simpática aumenta a transcrição do Slc2a4 no diabetes, porém a proteína só aumenta no músculo glicolítico. Estes resultados indicam que o comprometimento da expressão do Slc2a4 induzido pelo diabetes é menor em animais SHR, provavelmente devido a sua hiper-atividade simpática presente no músculo esquelético.

Palavras-chave: Slc2a4. GLUT4. Diabetes mellitus. Atividade simpática $\beta$-adrenérgica. 


\begin{abstract}
ALVES-WAGNER A. B. T. The effect of hypertension and diabetes association on Slc2a4/GLUT4 expression, possible $\beta$-adrenergic sympathetic nervous system participation. 2012. 68 p. Ph. D. thesis (Human Physiology) Instituto de Ciências Biomédicas, Universidade de São Paulo, São Paulo, 2012.

Slc2a4 gene, which encodes the GLUT4 protein, is expressed in insulin-sensitive tissues, such as muscle cells and adipocytes. Altered GLUT4 expression is directly correlated with alterations in glycemic homeostasis. We have demonstrated that the $\beta$-adrenergic system regulates GLUT4 expression during fasting; nevertheless its role in diabetes is not clearly understood. Considering that diabetic subjects can develop autonomic neuropathy, we hypothesize that changes in $\beta$ adrenergic activity could modulate diabetes-induced regulation of Slc2a4/GLUT4 expression. This study investigated the participation of sympathetic nervous system in the regulation of Slc2a4/GLUT4 expression in skeletal muscle of diabetic-Wistar rats and diabetic-spontaneously hypertensive rats (SHR), the latter presenting high sympathetic activity in the skeletal muscle. Firstly, Wistar, Wistar-Kyoto and SHR rats, were rendered diabetic, and one month later the Slc2a4 mRNA and GLUT4 protein were analyzed in soleus (oxidative) and extensor digitorum longus (EDL, glycolytic) skeletal muscle, comparing with respective non-diabetic animals. Diabetes significantly reduced Slc2a4 mRNA and GLUT4 protein in Wistar, as expected. However, that was not observed in diabetic Wistar-Kyoto and SHR. Thus, Wistar rats were chosen as controls for the SHR. Diabetic-Wistar (W-normotensive) and diabetic-SHR (Shypertensive) rats were treated with saline (S), insulin (I), propranolol (P) and propranolol+insulin (PI) for 1 week, after being kept diabetic for 1 month. As expected, insulin treatment reduced glycemia, urinary volume and glucose, and increased body weight in both SHR and Wistar. Propranolol, in a dose enough to reduce arterial blood pressure in hypertensive rats, did not alter the metabolic parameters. Insulin increased Slc2a 4 mRNA expression in soleus muscle of both groups; whereas propranolol reduced it only in Wistar rats. Conversely, in EDL muscle, insulin decreased whereas propranolol increased the mRNA expression. The association of propranolol+insulin showed that in soleus the effect of insulin was preponderant, whereas in EDL propranolol attenuates the effect of insulin. Importantly, despite the changes induced by treatments, Slc2a4 expression in both muscles was always higher in SHR than in the respective Wistar group. Finally, the GLUT4 protein expression was regulated similarly to the mRNA
\end{abstract}


modulation, with some specific discrepancies, indicating post-transcription regulation, or Tnfarelated alteration. SHR showed an increase in $\beta_{2}$-adrenergic protein expression only in soleus muscle. In conclusion, high sympathetic activity increases Slc2a4 expression in soleus and EDL, however the GLUT4 protein increased only in EDL. These results show that the decrease in Slc2a4 expression during diabetes is preserved in SHR, probably because their high sympathetic activity in skeletal muscle.

Keywords: Slc2a4. GLUT4. Diabetes mellitus. $\beta$-adrenergic sympathetic activity. 


\section{SUMÁRIO}

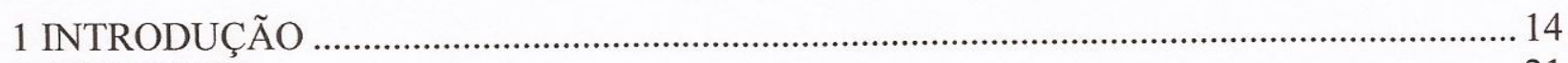

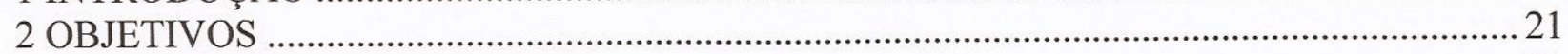

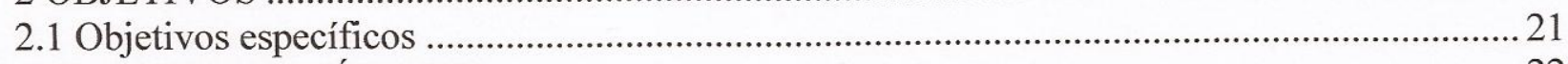

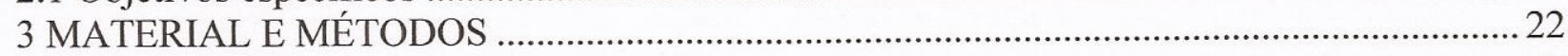

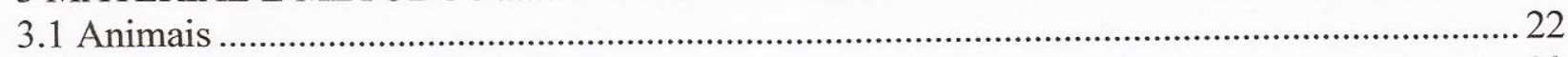

3.2 Tratamento para indução de diabetes .................................................................................. 23

3.3 Tratamentos com insulina e antagonista $\beta$-adrenérgico (estudo 2) ........................................ 23

3.4 Coleta das amostras de sangue e tecido .......................................................................... 24

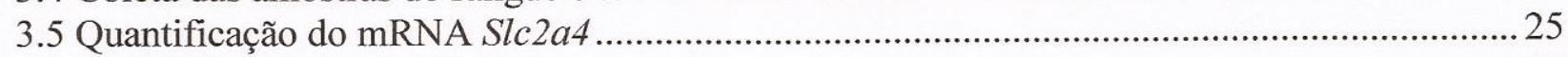

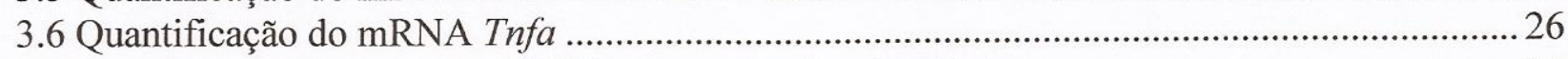

3.7 Quantificação da proteína GLUT4 e receptor $\beta_{2}$-adrenérgico .............................................. 27

3.8 Determinação da concentração plasmática de ácidos graxos livres...................................... 30

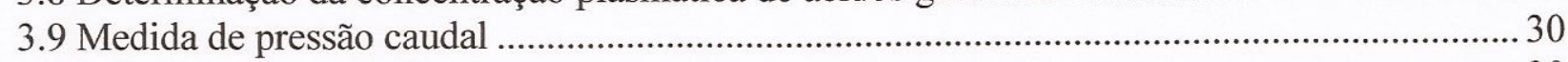

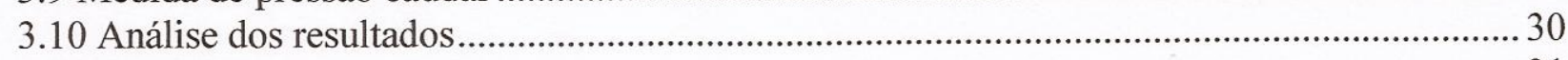

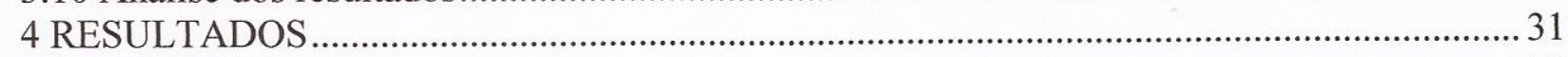

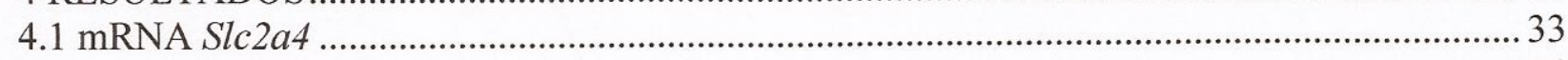

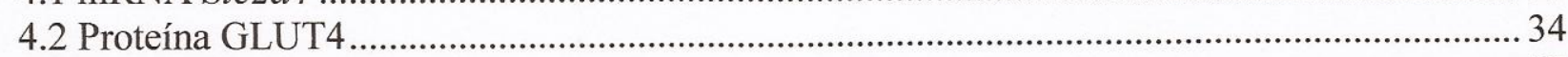

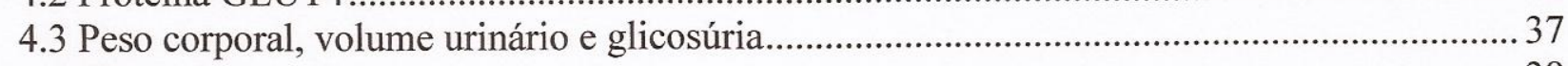

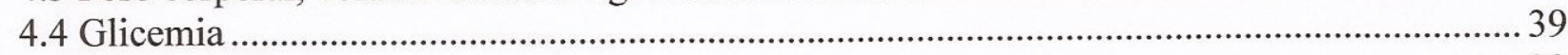

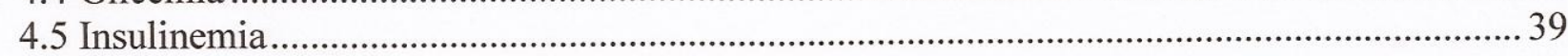

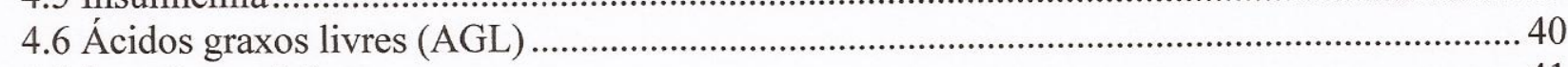

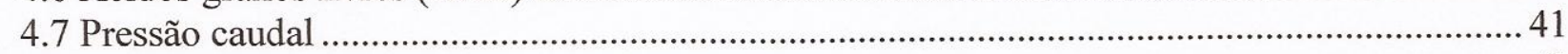

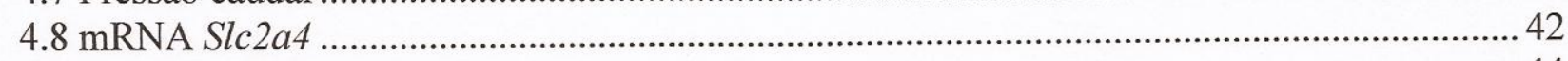

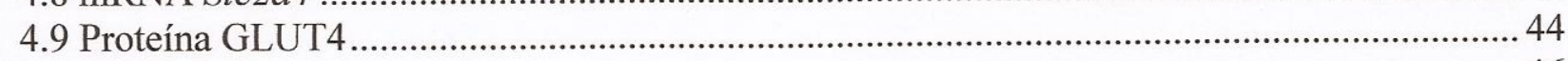

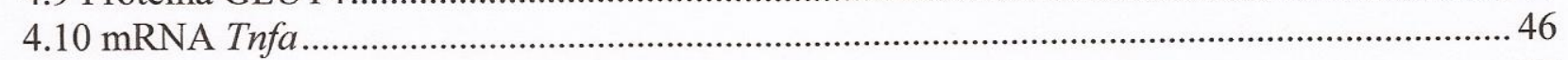

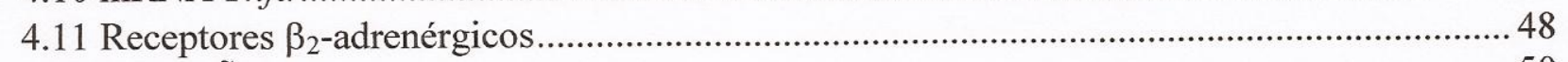

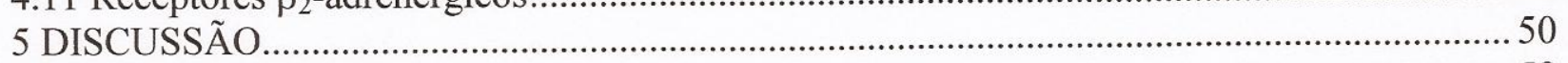

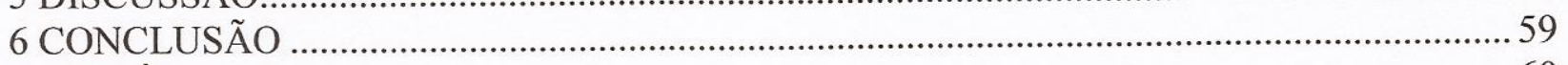

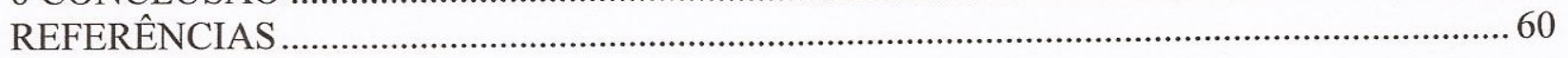




\section{INTRODUÇÃO}

O Slc2a4 (Solute carrier 2a4) é o gene que codifica a proteína GLUT4 (glucose transporter 4), que é um transportador de glicose responsivo à insulina, e que está localizado principalmente em células musculares e adiposas (SHEPHERD; KAHN, 1999), tecidos com alta capacidade de captação de glicose quando o substrato está disponível abundantemente, tal como no período pós-prandial, no qual a proteína é translocada para a membrana plasmática sob estímulo insulínico (THORENS et al., 1990). Modificações na expressão deste gene, em músculo esquelético e em tecido adiposo, correlacionam-se de maneira direta com aumento ou redução da sensibilidade à insulina (THORENS et al., 1990).

O tecido muscular esquelético é o maior local envolvido na captação de glicose dependente de insulina, responsável por $\sim 80 \%$ da captação de glicose pós-prandial (BARON et al., 1988), a qual é mediada pelo GLUT4.

O tecido muscular esquelético sóleo é constituído principalmente por fibras musculares vermelhas de contração lenta, oxidativa, do tipo I; enquanto que o extensor digital longo (EDL) é constituído principalmente por fibras musculares brancas de contração rápida, glicolítica, do tipo IIB. Existe uma notável heterogeneidade na sensibilidade e responsividade à insulina entre as diferentes fibras musculares (JAMES; JENKINS; KRAEGEN, 1985), sendo as fibras musculares vermelhas mais sensíveis e responsivas à insulina que fibras musculares brancas (KERN et al., 1990). O transporte de glicose e o conteúdo de GLUT4 são maiores no músculo vermelho que no músculo branco (KERN et al., 1990).

$\mathrm{O}$ tecido adiposo branco (WAT, white adipose tissue), além de armazenar substrato energético, é capaz de produzir hormônios. O WAT é controlado por interações de fatores humorais (hormônios e substratos) e neurais (sistema nervoso autonômico). Este tecido estoca grande quantidade de triglicerídeos. Insulina e adrenalina são os maiores reguladores do metabolismo do tecido adiposo, entretanto, outros fatores, como glucagon, cortisol e o hormônio do crescimento $(\mathrm{GH})$ também exercem um efeito sobre ele. A insulina estimula a captação de glicose e ácidos graxos no WAT e, simultaneamente estimula a lipogênese e inibe a lipólise. A adrenalina aumenta a lipólise por meio da estimulação da lipase hormônio sensível aumentando a liberação de ácidos graxos e glicerol (FLIERS et al., 2003). 
O aumento de ácidos graxos livres está tipicamente associado com estados de resistência à insulina, incluindo obesidade e diabetes mellitus (SHULMAN, 2000). Em um estudo com indivíduos jovens, não obesos, filhos de pacientes com diabetes mellitus tipo 2 , foi encontrado uma relação inversa entre a concentração de ácidos graxos livres durante o jejum e a sensibilidade à insulina (PERSEGHIN et al., 1997). Além disso, estudos que mediram o conteúdo de triglicerídeo intramuscular (PAN et al., 1997) e intramiocelular (KRSSAK et al., 1999) mostraram uma forte relação entre acúmulo de triglicerídeo intramiocelular e resistência à insulina.

O diabetes mellitus é uma síndrome de etiologia múltipla, decorrente da falta de insulina e/ou da incapacidade da insulina exercer adequadamente seus efeitos. Caracteriza-se pela presença de hiperglicemia inapropriada e, frequentemente, por complicações crônicas degenerativas (MASHARANI; KARAM, 2001). O diabetes mellitus é atualmente classificado em tipo 1 (T1DM) ou tipo 2 (T2DM), na maioria dos casos. O T1DM é caracterizado pela destruição, quase sempre por um mecanismo imunológico, das células beta pancreáticas; já o T2DM parece ser consequência de resistência à insulina, e com frequência está associado a obesidade, principalmente visceral, e falta de exercícios (WHITE, 2009).

Foi demonstrado por Camps et al. (1992) que o diabetes experimental, induzido por streptozotocina, leva a uma diminuição na expressão do transportador de glicose GLUT4 no tecido adiposo branco e marrom, e nos músculos cardíaco e esquelético, porém o mRNA aumenta no músculo branco e diminui no vermelho (CAMPS et al., 1992). Modelo experimental de T2DM, como camundongo tratado com glutamato monossódico, também revelou diminuição da proteína GLUT4 em tecidos adiposo branco, músculo esquelético e coração (MACHADO et al., 1993).

Aloxana e streptozotocina são os químicos diabetogênicos mais conhecidos e usados na pesquisa de diabetes insulino-privo. Ambos são citotóxicos análogos de glicose, e apesar da citotoxicidade ser ativada por vias diferentes, a aloxana gera espécies reativas de oxigênio e a streptozotocina causa o consumo excessivo de ATP celular; os mecanismos de lesão seletiva das células beta pancreáticas são idênticos, sendo causados por necrose celular (LENZEN, 2008).

A etiologia da hipertensão arterial é multifatorial e o estado de resistência à insulina é um fator postulado para predispor pacientes ao desenvolvimento da hipertensão arterial (BROWNLEE et al., 2002). Define-se hipertensão arterial como pressão arterial sistólica maior 
ou igual a $140 \mathrm{mmHg}$, pressão diastólica maior ou igual a $90 \mathrm{mmHg}$, ou a necessidade de utilização de medicação anti-hipertensiva (JOINT NATIONAL COMMITEE, 2004). Além disso, há um estado de pré-hipertensão, denominada quando a pressão arterial sistólica está entre 120-139 mmHg e a diastólica entre $80-89 \mathrm{mmHg}$, que exige uma mudança no estilo de vida (como por exemplo perda de peso, dieta saudável com redução de sódio, e exercício físico) para evitar o desenvolvimento da hipertensão (JNC, 2004).

Hipertensão arterial contribui para causas que levam a morbidade e mortalidade em pacientes com diabetes, principalmente o T2DM, incluindo doença coronariana, acidente vascular cerebral, doença vascular periférica, amputação de extremidades, doença renal e retinopatia (COOPER et al., 2001; JNC, 2004). Por essas razões, hipertensão arterial e diabetes devem ser tratadas com rapidez e agressividade.

O modelo genético de hipertensão arterial espontânea em ratos, desenvolvido por Okamoto e Aoki, denominado SHR (Spontaneously Hypertensive Rats), é o que mais se aproxima da hipertensão essencial no homem. Os SHRs foram desenvolvidos por cruzamento genético de ratos Wistar-Kyoto, no qual se conseguiu estabelecer uma colônia de ratos que desenvolveram hipertensão espontânea em 100\% dos descendentes. Os SHRs nascem normotensos, mas começam a desenvolver hipertensão arterial espontaneamente ao redor da quarta semana de vida. A pressão arterial se eleva gradualmente nas semanas seguintes atingindo níveis de hipertensão grave, que se mantém por toda a vida do animal (OKAMOTO; AOKI, 1963).

Em SHR, já foi demonstrado que a ativação simpática neuronal está aumentada em músculo esquelético e tecido adiposo subcutâneo durante todo o curso natural de vida $(5,16,30$ e 54 semanas de vida), em animais acordados e com livre movimentação (CABASSI et al., 2002). Isso mostra que além da hipertensão, esses animais possuem uma maior atividade simpática no músculo esquelético e tecido adiposo subcutâneo.

Há controvérsias quanto ao controle que deva ser usado quando se estuda a homeostase glicêmica em animais com hipertensão arterial espontânea (SHR), já que foi demonstrado que os ratos Wistar-Kyoto, assim como os SHR, possuem intolerância à glicose (KATAYAMA et al., 1997).

Alterações na expressão do gene Slc2a4 já foram mostradas em modelos experimentais de hipertensão arterial, como SHR (KATAYAMA et al., 1997; PATERNOSTRO et al., 1995) e Milan (CAMPBELL et al., 1995). Alguns autores encontraram uma diminuição na expressão de 
GLUT4 nas membranas intracelulares de músculo esquelético de animais hipertensos (CAMPBELL et al., 1995), enquanto outros autores mostraram um aumento na expressão do mRNA, sem alterar a expressão da proteína GLUT4 em músculo esquelético gastrocnêmio (KATAYAMA et al., 1997). Estes estudos indicam que a regulação do Slc2a4/GLUT4 em modelos de hipertensão é variável.

Foi demonstrado que a insulina exerce uma ação no sistema nervoso autônomo, incluindo estimulação da atividade simpática no músculo de indivíduos saudáveis (BERNE et al., 1992), além disso, autores mostraram que indivíduos resistentes à insulina, como ocorre na hipertensão essencial e obesidade, possuem uma atividade simpática basal elevada (TENTOLOURIS; ARGYRAKOPOULOU; KATSILAMBROS, 2008). Resistência à insulina, hiperinsulinemia compensatória e ativação do sistema nervoso simpático tem sido sugeridos como sendo os principais responsáveis pela alta prevalência de hipertensão arterial em pacientes diabéticos (FRONTONI; BRACAGLIA; GIGLI, 2005).

Os efeitos do sistema nervoso simpático no metabolismo de glicose e lipídios são mediados pela concentração plasmática de adrenalina e pela inervação simpática direta no fígado, tecido adiposo e músculo esquelético (NONOGAKI, 2000). Os neurônios pósganglionares simpáticos liberam noradrenalina, que excita algumas células efetoras, mas inibe outras, enquanto a medula adrenal libera primordialmente adrenalina (WILLIS Jr, 2004).

Os receptores adrenérgicos são proteínas transmembrânicas com a terminação amino extracelular e a terminação carboxil intracelular, possuindo 7 regiões hidrofóbicas na membrana celular. Os receptores adrenérgicos são divididos em $\alpha_{1},\left(\alpha_{1 \mathrm{~A}}, \alpha_{1 \mathrm{~B}}\right.$ e $\left.\alpha_{1 \mathrm{D}}\right), \alpha_{2}\left(\alpha_{2 \mathrm{~A}}, \alpha_{2 \mathrm{~B}}\right.$ e $\left.\alpha_{2 \mathrm{C}}\right)$ e $\beta$ $\left(\beta_{1}, \beta_{2}, \beta_{3 \mathrm{a}}\right.$ e $\left.\beta_{3 \mathrm{~b}}\right)$ (GOLDFIEN, 2001; HUTCHINSON et al., 2002). Os receptores $\alpha_{1}$ agem nas células alvo por proteína Gq, já os receptores $\alpha_{2}$ agem por meio de proteína Gi, enquanto que os receptores $\beta$ agem por meio de Gs $\left(\beta_{1}, \beta_{2}\right.$ e $\left.\beta_{3}\right)$ e/ou Gi $\left(\beta_{2}\right.$ e $\left.\beta_{3}\right)$ (EVANS et al., 1999; GOSMANOV; WONG; THOMASON, 2002; LYNCH; RYALL, 2008; XIAO et al., 1999). Portanto, os receptores $\alpha_{1}$ aumentam o 1,4,5-inositol trifosfato e diacilglicerol intracelulares, os $\alpha_{2}$ diminuem o AMPc intracelular e os receptores $\beta$ aumentam e/ou diminuem o AMPc intracelular nos tecidos alvo (GOLDFIEN, 2001).

O tecido muscular esquelético possui os 3 subtipos de receptores $\beta$-adrenérgicos $(1,2$ e 3), porém apresenta predominantemente o subtipo $\beta_{2}$ (KIM et al., 1991). O tecido adiposo branco apresenta os 3 subtipos de receptores $\beta$-adrenérgicos, porém predominantemente o receptor $\beta_{3}$ 
( $90 \%$ da população de adrenoceptores), sendo os 3 capazes de induzir a lipólise $\left(\beta_{3}>>\beta_{1}>\beta_{2}\right)$ (GERMACK et al., 1997). Comparando-se os receptores $\beta$ - e $\alpha$-adrenérgicos, os receptores $\alpha$ adrenérgicos são esparsos no músculo esquelético (RATTIGAN et al., 1986), enquanto no tecido adiposo branco está presente o receptor $\alpha_{2}$, e uma pequena quantidade de receptor $\alpha_{1}$ (LAFONTAN; BERLAN, 1993).

A via de sinalização mais conhecida dos receptores $\beta$-adrenérgicos é a da proteína quinase A (PKA), que foi caracterizada em diversos tipos celulares (LYNCH; RYALL, 2008). No músculo esquelético a ativação desta via parece ser, pelo menos em parte, responsável pela resposta anabólica gerada pelo estímulo $\beta$-adrenérgico (LYNCH; RYALL, 2008). Foi demonstrado que a administração de inibidores de fosfodiesterase (gerando aumento de AMPc intracelular) reduz o catabolismo proteico no músculo esquelético de ratos, podendo envolver uma via indireta, inibindo a superprodução de TNF $\alpha$ em ratos sépticos; ou agindo diretamente na via da PKA (LIRA et al., 2007), dependendo do inibidor utilizado.

TNF é uma citocina produzida em grandes quantidades por macrófagos, sendo também produzido por tecido adiposo e músculo esquelético (SAGHIZADEH et al., 1995). Estudos recentes revelaram que o TNF- $\alpha$ não só possui um papel na regulação da inflamação, apoptose e sobrevivência celular, citotoxicidade e produção de outras citocinas (IL-1 e IL6), como também na indução da resistência à insulina induzida pela obesidade (NIETO-VAZQUEZ et al., 2008). Foi demonstrado que o TNF- $\alpha$ regula a expressão gênica, via NF- $\kappa B$, de genes como: adiponectina, GLUT4, IRS-1, C/EBP $\alpha$, PPAR $\gamma$ e perilipin em adipócitos (NIETO-VAZQUEZ et al., 2008).

A descoberta do Epac (exchange protein activated directly by cAMP) mostrou uma nova via de sinalização ativada pelos receptores $\beta$-adrenérgicos e AMPc, qual já foi descrita em músculo esquelético (LYNCH; RYALL, 2008). Estudos preliminares mostram que ativação do Epac potencializa a resposta celular à insulina, através da ativação da PI3K e AKT via Rap-1 (LYNCH; RYALL, 2008).

Foi demonstrado por nosso laboratório, que a atividade simpática $\beta$-adrenérgica mantém a expressão do GLUT4 no músculo glicolítico durante o jejum (ALVES-WAGNER et al., 2009), evidenciando a participação do sistema nervoso simpático na regulação do gene Slc2a4 em músculo esquelético. 
Estudos mostraram que o diabetes diminui a expressão dos receptores $\beta_{1}$-adrenérgicos e aumenta dos receptores $\beta_{3}$-adrenérgicos no coração, o que pode estar envolvido com o desenvolvimento de disfunção cardíaca induzida pelo diabetes, o que é revertido parcialmente com tratamento com insulina (DINÇER et al., 2001). Porém, ainda não está claro se ocorre essa modulação em músculo esquelético.

$\mathrm{O}$ aumento da atividade simpática e o aumento da concentração de catecolaminas circulantes estão envolvidos com a gênese e a manutenção de estados patológicos que acometem o sistema cardiovascular, entre eles a hipertensão arterial essencial (ESLER; KAYE, 2000), tanto em humano como em modelo animal (GUYENET, 2006). Por outro lado, neuropatia autonômica diabética é uma complicação frequente do diabetes, ainda pouco conhecida e entendida, apesar do alto impacto negativo na sobrevivência e qualidade de vida das pessoas portadoras de diabetes (VINIK et al., 2003). A neuropatia autonômica diabética pode afetar o sistema nervoso autônomo inteiro, ou seja, as fibras simpáticas e parassimpáticas. A neuropatia autonômica é manifestada pela disfunção de um ou mais órgãos ou sistemas (VINIK et al., 2003). Complicações do sistema nervoso autonômico podem ser detectadas nos primeiros anos após o diagnóstico do diabetes, e as principais manifestações são disfunções cardiovasculares, gastrointestinais e do sistema urinário (BROWNLEE et al., 2002). Redução na tolerância ao exercício, edema, hipertensão noturna, intolerância ao calor devido a um desequilíbrio na termorregulação, são consequências da neuropatia autonômica (BROWNLEE et al., 2002). A neuropatia autonômica diabética pode ser a precursora da morte precoce, que ocorre numa larga proporção de pacientes afetados (CRYER, 1986).

A neuropatia autonômica, assim como outras complicações que ocorrem no diabetes, provavelmente depende da manutenção de alta glicemia por um longo período de tempo (VINIK et al., 2003).

Já foi demonstrado que ratos hipertensos (PATERNOSTRO et al., 1995) e ratos diabéticos (CAMPS et al., 1992) possuem alterações na expressão do Slc2a4/GLUT4, mas não se estudou o efeito da associação diabetes hipertensão arterial. Também já se observou que o sistema $\beta$-adrenérgico atua na expressão do GLUT4 durante o jejum (ALVES-WAGNER et al., 2009), o que poderia participar dos efeitos do diabetes e/ou hipertensão. Por isto, neste trabalho investigamos se a hiperatividade simpática, como é o caso do SHR, regula a expressão do GLUT4 no diabetes. Além disso, sendo o propranolol um bloqueador $\beta$-adrenérgico utilizado na 
prática clínica, é importante investigar seus efeitos sobre a homeostasia glicêmica, sobretudo quando diabetes/neuropatia estiverem associados. 


\section{OBJETIVOS}

Investigar a participação do sistema nervoso autônomo simpático $\beta$-adrenérgico sobre a expressão do gene Slc2a4 e da proteína GLUT4 em músculo esquelético de ratos diabéticos e/ou hipertensos.

\subsection{Objetivos específicos}

a) Investigar qual o melhor controle para estudo de ratos SHR diabéticos. Para isto analisamos a expressão do mRNA Slc2a4 e da proteína GLUT4 em músculo esquelético oxidativo (sóleo) e glicolítico (EDL) de animais Wistar, Wistar-Kyoto e SHR não diabéticos e diabéticos por 1 mês. b) Investigar o efeito do propranolol em ratos diabéticos e/ou hipertensos. Para isto utilizamos apenas animais diabéticos, normotensos (Wistar) e hipertensos (SHR), tratados ou não com insulina e/ou propranolol (antagonista $\beta_{1}$ - e $\beta_{2}$-adrenérgicos) por 7 dias (após 1 mês de diabetes), e analisamos a expressão do mRNA Slc2a4 e da proteína GLUT4 em músculo oxidativo (sóleo) e glicolítico (EDL). 


\section{MATERIAL E MÉTODOS}

\subsection{Animais}

Foram utilizados ratos Wistar, Wistar-Kyoto e SHR (espontaneamente hipertensos) de 12 semanas (fornecidos pelo Biotério Central do Intituto de Ciências Biomédicas, Universidade de São Paulo), acondicionados em biotério termorregulado $\left(23{ }^{\circ} \mathrm{C} \pm 2{ }^{\circ} \mathrm{C}\right)$, com ciclo de luz/escuridão 12/12 horas (início do período claro às 6 h) e água e alimentação à vontade.

Nestes animais foi induzido ou não o diabetes, para serem estudados 1 mês depois.

No estudo 1, após 1 mês de diabetes, os animais foram divididos nos seguintes grupos experimentais: Wistar (W), Wistar diabético (WD), Wistar-Kyoto (K), Wistar-Kyoto diabético (KD), SHR (S) e SHR diabético (SD).

No estudo 2, após 1 mês de diabetes, os animais foram divididos em oito grupos experimentais, descritos no quadro 1.

Quadro 1- Grupos experimentais do estudo 2.

\begin{tabular}{|lll|lll|}
\hline \multicolumn{3}{|c|}{ Ratos Wistar diabéticos } & \multicolumn{3}{|c|}{ Ratos SHR diabéticos } \\
\hline WS: Normotenso diabético tratado com salina & SS: Hipertenso diabético tratado com salina \\
\hline $\begin{array}{l}\text { WI: Normotenso diabético tratado com } \\
\text { insulina }\end{array}$ & SI: Hipertenso diabético tratado com insulina \\
\hline $\begin{array}{l}\text { WP: Normotenso diabético tratado com } \\
\text { propranolol }\end{array}$ & $\begin{array}{l}\text { SP: Hipertenso diabético tratado com } \\
\text { propranolol }\end{array}$ & & com \\
\hline $\begin{array}{l}\text { WPI: Normotenso diabético tratado com } \\
\text { propranolol+insulina }\end{array}$ & $\begin{array}{l}\text { SPI: Hipertenso diabético tratado com } \\
\text { propranolol+insulina }\end{array}$ & & \\
\hline
\end{tabular}

Fonte: Alves-Wagner (2012).

O controle de peso corporal dos animais foi feito através de 3 pesagens:

a) peso no dia da indução do diabetes;

b) peso no dia da eutanásia (estudo 1) ou no início do tratamento (estudo 2);

c) peso no dia da eutanásia, após tratamento (estudo 2).

O protocolo experimental foi aprovado pela Comissão de Ética em Experimentação Animal (CEEA) do ICB, USP, protocolo n 015 - fls. 55- livro 02, ano 2008, renovado em 2011. 


\subsection{Tratamento para indução de diabetes}

O diabetes foi induzido por aloxana (Alloxan monohydrate - A7413, Sigma-Aldrich, Inc., St. Louis, USA), que é capaz de promover necrose específica das células beta da ilhota pancreática, em animais com 12 semanas de vida. A droga foi aplicada em uma dose de 38 $\mathrm{mg} / \mathrm{kg}$ (Wistar) ou $40 \mathrm{mg} / \mathrm{kg}$ (SHR) ou $42 \mathrm{mg} / \mathrm{kg}$ (Wistar-Kyoto) de peso corpóreo, por via endovenosa (veia peniana). O animal estava em jejum prévio de 12 horas, para aumentar a seletividade na célula beta e evitar os danos renais e hepáticos, e foi rapidamente sedado com éter etílico. Após 2 horas os animais foram alimentados com ração e foi oferecida água com sacarose (por 12 horas), evitando hipoglicemia.

Dentre os animais tratados com aloxana foram selecionados, após 1 mês, aqueles que apresentaram diurese acima de $40 \mathrm{~mL}$ em 24 horas, glicosúria acima de $50 \mathrm{mg} / \mathrm{dL}$ e que estavam em bom estado geral (ausência de caquexia e hiperventilação).

\subsection{Tratamentos com insulina e antagonista $\beta$-adrenérgico (estudo 2)}

Devido à condição experimental do diabetes, todos os animais foram colocados em gaiolas metabólicas durante o tratamento.

Os tratamentos abaixo só foram realizados nos animais do estudo 2, estando exemplificado na figura 1 .

a) Administração de insulina

A insulina (NPH, Humulin ${ }^{\circledR}$, Eli Lilly and Company, Indianápolis, EUA) foi administrada por via subcutânea em 2 injeções diárias, numa dose total de $6 \mathrm{U} / \mathrm{dia}$, sendo $2 \mathrm{U}$ às 8 hs e 4 U às 17 hs (FREITAS et al., 2005). Os animais diabéticos não tratados receberam salina nas mesmas condições.

b) Administração do antagonista $\beta$-adrenérgico

O bloqueador $\beta$-adrenérgico utilizado foi o propranolol, antagonista dos receptores $\beta_{1}$ - e $\beta_{2}$-adrenérgicos. O tratamento com cloridrato de DL-propranolol (P0884 - Sigma-Aldrich, Inc., St. Louis, USA) foi por via intraperitonial, $8 \mathrm{mg} / \mathrm{kg}$ de peso corporal, $2 \mathrm{X}$ ao dia ( $7 \mathrm{hs}$ e $19 \mathrm{hs}$ ), por 7 dias (KIMURA; MIYAMOTO; OHSHIKA, 1993). O propranolol foi diluído em solução 
ácida (citrato de sódio $\mathrm{pH}=3.0$ ), por ser estável em $\mathrm{pH}=3.0$, sendo decomposto rapidamente em pH básico. Os animais não tratados receberam citrato de sódio nas mesmas condições.

Figura 1- Esquema do tratamento com insulina e/ou propranolol feito nos animais do estudo 2 (Wistar e SHR diabéticos).

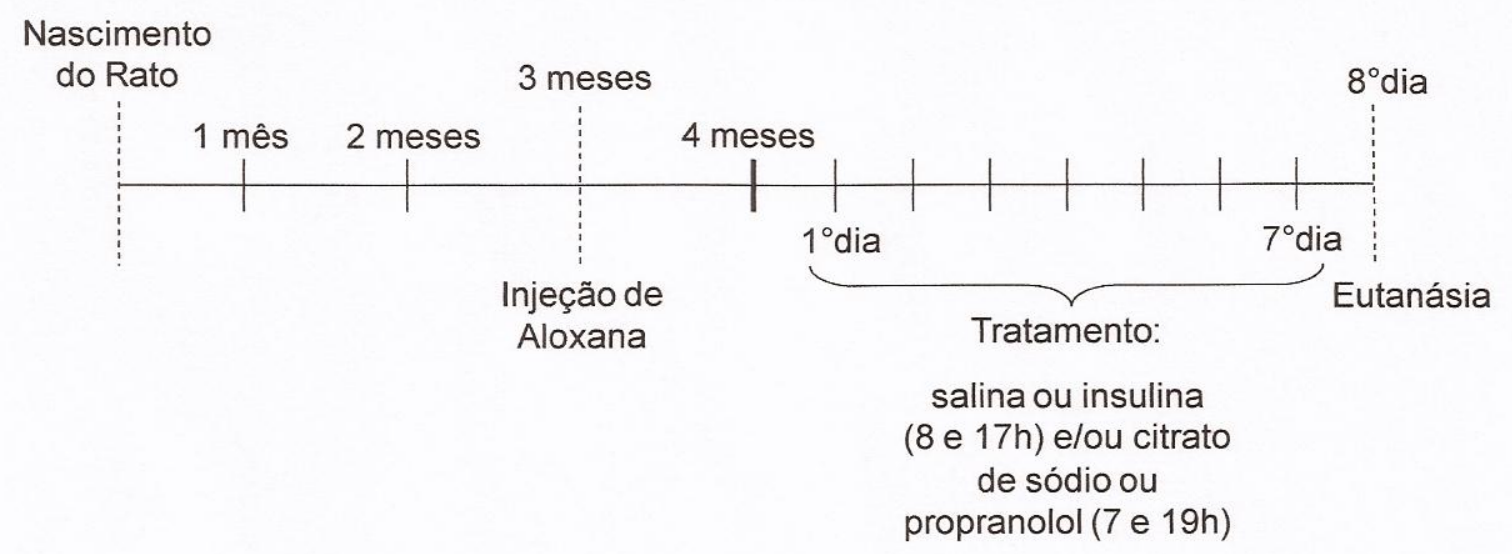

Fonte: Alves-Wagner (2012).

\subsection{Coleta das amostras de sangue e tecido}

Os animais foram anestesiados (tiopental sódico, $5 \mathrm{mg} / 100 \mathrm{~g}$ de peso corporal, intraperitonial - Thiopentax ${ }^{\circledR}$, Cristália, Itapira, SP, Brasil) para retirada de amostras de sangue e tecidos. O sangue, coletado da veia cava inferior, foi utilizado para análise da concentração de glicose em sangue total (glicosímetro - Precision Q.I.D., Medisense, Abbot Laboratory Company, Bedford, Massachusetts, USA), dosagem de insulina plasmática (radioimunoensaio Coat-a-Coat, Diagnostic Products Corporation, Los Angeles, USA) e dosagem de ácidos graxos no plasma (metodologia descrita posteriormente). Foi feita a dissecação das patas e os tecidos musculares esqueléticos sóleo e EDL foram excisados. Mantidas em freezer a $-75^{\circ} \mathrm{C}$, as amostras foram utilizadas para análise do conteúdo de mRNA Slc2a4 e Tnfa por Northern Blotting e PCR, respectivamente, e do conteúdo de proteína GLUT4 e receptores $\beta_{2}$-adrenérgico por Western Blotting.

Após a retirada dos tecidos os animais foram mortos com superdosagem do anestésico (tiopental sódico - Thiopentax ${ }^{\circledR}$, Cristália, Itapira, SP, Brasil). 


\subsection{Quantificação do mRNA Slc2a4}

a) Preparação dos tecidos para o Northern Blotting

Os tecidos foram homogeneizados em TRIZOL Reagent® (LIFE TECHNOLOGIES GIBCO BRL, Gaithersburg, USA) e centrifugados. Ao sobrenadante foi adicionado clorofórmio, e após outra centrifugação, no qual obteve-se outro sobrenadante, adicionou-se isopropanol. Após a centrifugação final o precipitado foi lavado com etanol 70\%, e foi adicionada água DEPC (Dietil Pirocarbonato) para solubilização do precipitado final a $65^{\circ} \mathrm{C}$, e após foi colocado em gelo por 5 minutos.

b) Avaliação da concentração de RNA total

Foi retirado $1 \mu \mathrm{l}$ da amostra e adicionados $79 \mu \mathrm{l}$ de água DEPC para leitura em espectrofotômetro (Gene Quant, Amershan Pharmacia Biotech, Buckinghamshire, UK) em 260 nm. Essa leitura permitiu o cálculo da concentração de ácido nucléico da amostra. Uma unidade de densidade óptica (DO) corresponde a aproximadamente $40 \mu \mathrm{g} / \mathrm{ml}$ de fita simples e a relação DO 260/DO 280, sempre > 1,65, permite estimar a pureza do ácido nucléico da amostra.

c) Northern Blotting

A avaliação do mRNA Scl2a4 foi feita através da técnica de Northern Blotting (DAVIS; KUEHL; BATTEY, 1994), sumarizada a seguir:

\section{- Eletroforese}

Vinte $\mu \mathrm{g}$ de RNA total de músculo foram precipitados por centrifugação a vácuo. "Running Buffer" 10X (MOPS 0,2 M, EDTA 10 mM, NaOAc 50 mM, pH 7,0); formaldeído e formamida foram adicionados ao RNA total e incubados a $65^{\circ} \mathrm{C}$, e em seguida colocados em gelo. Foram adicionados 2,5 $\mu \mathrm{l}$ de tampão de aplicação ("loading buffer": glicerol 30\%; azul de bromofenol 0,025\% em água DEPC) e $2 \mu$ de brometo de etídio (diluído 1:20).

A eletroforese para separação do RNA total foi realizada sob corrente constante de 400 $\mathrm{mA}, 100 \mathrm{~V}$, em gel analítico de agarose 1,3\% (agarose 0,78 g, água DEPC 43,8 ml, $6 \mathrm{ml}$ "Running Buffer" 10X, 10,2 ml formaldeído) durante aproximadamente 3 horas, em um sistema de eletroforese horizontal submersa em "Running Buffer" 1X (Tampão de corrida).

\section{- Transferência}

As amostras foram transferidas para a membrana de nylon Hybond ${ }^{\circledR} \mathrm{N}$ (Amesham Biosciences, Buckinghamshire, UK) através do método de transferência por capilaridade, 
durante aproximadamente 18 horas. O RNA foi fixado à membrana através da radiação ultravioleta $254 \mathrm{~nm}$, por 3 minutos.

- Hibridação

Foram utilizados $25 \mathrm{ng}$ de cDNA do Slc2a4 e/ou $\beta$-actina, $25 \mu \mathrm{Ci}$ de $\alpha^{32}$-P dCTP (Redivue-Tip $\alpha-{ }^{32} \mathrm{P}$ dCTP-Amersham Biosciences), e o kit Random Primers DNA Labeling System (Invitrogen ${ }^{\mathrm{TM}}$ Life Technologies, Gaithersburg, USA) para obtenção da sonda radioativa utilizada na hibridação. A membrana foi pré-hibridada em $100 \mu \mathrm{g} / \mathrm{ml}$ de DNA de esperma de salmão desnaturado, durante 3 horas, a $60{ }^{\circ} \mathrm{C}$. Após, a membrana foi hibridada em solução tampão de hibridação $\left(\mathrm{NaH}_{2} \mathrm{PO}_{4} \cdot \mathrm{H}_{2} \mathrm{O} 0,5 \mathrm{M}\right.$; $\mathrm{Na}_{2} \mathrm{HPO}_{4} \cdot 7 \mathrm{H}_{2} \mathrm{O}$ 0,5 M; SDS $10 \%$; EDTA 0,5 M; $1 \%$ BSA) com a sonda radioativa, durante 20 horas a $60^{\circ} \mathrm{C}$.

- Autorradiografia e densitometria

A membrana de nylon foi exposta a filme (Kodak X-Omat LS, Kodak Company, Rochester, NY) durante aproximadamente 4 dias, a $-70{ }^{\circ} \mathrm{C}$. O filme foi revelado em solução reveladora e reforçadora GBX (Kodak Brasileira, São Paulo, BR) e fixado em solução fixadora e reforçadora GBX (Kodak Brasileira, São Paulo, BR).

A intensidade do "blots" foi avaliada por densitometria óptica, utilizando-se o "software" Image master 1D (Pharmacia Biotech, Uppsala, SW).

- Normalização dos valores

Para correção das quantidades de RNA total aplicado na eletroforese, os valores em unidades arbitrárias (UA) obtidos dos "blots" de mRNA do transportador foram normalizados pelos respectivos valores de UA da $\beta$-actina.

- Expressão dos resultados

Os resultados foram expressos em unidades arbitrárias, a partir dos valores normalizados pela $\beta$-actina, e considerando 100 o valor obtido em cada experimento para o controle $\mathrm{W}$ (estudo 1) ou WS (estudo 2).

\subsection{Quantificação do mRNA Tnfa}

A reação de transcrição reversa foi realizada a partir de $1 \mu \mathrm{g}$ de RNA total, com primers randômicos e enzima Improm II (Promega, Madison, WI, EUA). A partir dos cDNAs obtidos, 
foram realizadas as curvas de ciclos de amplificação para cada primer, com 8 pontos para cada curva. Os experimentos foram realizados com um número de ciclos abaixo do ponto de saturação (platô), utilizando-se GoTaq Green Master Mix (Promega, Madison, WI, EUA). Para o gene estudado foi realizado, em paralelo, a amplificação de um gene constitutivo (Gapdh). Os produtos amplificados foram submetidos à eletroforese em gel de agarose-EtBr e visualizados com iluminação UV. As imagens, adquiridas em equipamento de fotovideodocumentação (UVP Biolmagin System), foram submetidas à análise densitométrica com o software Image Quant IT (GE Healthcare Biosciences, Upsalla, Sweden). A expressão do gene alvo foi normalizada pela expressão do gene constitutivo.

O experiment foi realizado 2 vezes, para confirmação do resultado final.

As sequências dos primers e condições para amplificação encontram-se na tabela 1 .

Tabela 1- Primers utilizados para quantificação da expressão de mRNA de diferentes genes por PCR.

\begin{tabular}{|c|c|c|c|c|}
\hline Primer & Sequência $\left(5^{\prime} \rightarrow 3^{\prime}\right)$ & $\mathrm{T}_{\mathrm{m}}\left({ }^{\circ} \mathrm{C}\right)$ & Ciclos & $\begin{array}{l}\text { Tamanho } \\
\text { do produto } \\
\text { (bp) }\end{array}$ \\
\hline $\begin{array}{c}\text { Tnfa } \\
\text { Forward }\end{array}$ & CGTCAGCCGATTTGCCATTTC & 59 & $\begin{array}{l}35 \text { (sóleo) } \\
39 \text { (EDL) }\end{array}$ & 116 \\
\hline $\begin{array}{c}\text { Tnfa } \\
\text { Reverse }\end{array}$ & TGGGCTCATACCAGGGCTTGAG & 59 & $\begin{array}{l}35 \text { (sóleo) } \\
39 \text { (EDL) }\end{array}$ & 116 \\
\hline $\begin{array}{l}\text { Gapdh } \\
\text { Forward }\end{array}$ & ACATCATCCCTGCATCCACT & 55,7 & 34 & 258 \\
\hline $\begin{array}{c}\text { Gapdh } \\
\text { Reverse }\end{array}$ & GGGAGTTGCTGTTGAAGTCA & 55,7 & 34 & 258 \\
\hline
\end{tabular}

Fonte: Alves-Wagner (2012).

\subsection{Quantificação da proteína GLUT4 e receptor $\beta_{2}$-adrenérgico}

\section{a) Preparação dos tecidos para Western Blotting}

As amostras foram centrifugadas em tampão de homogeneização (Tris $\mathrm{HCl} 10 \mathrm{mM}$; EDTA 1,0 mM; sacarose $250 \mathrm{mM}$ ) numa proporção de 1:6 (peso:volume). O homogeneizado foi submetido a uma centrifugação $1.000 \mathrm{~g}$ durante 10 minutos, e o sobrenadante gerado foi submetido a uma ultracentrifugação (146.000 g durante 75 minutos). O pellet produzido foi ressuspendido em tampão de homogeneização, e representa uma fração de proteínas de 
membranas celulares que contém o GLUT4 e o receptor $\beta_{2}$-adrenérgico totais (membrana plasmática + microssoma).

b) Determinação da concentração de proteínas

A concentração de proteínas totais nas amostras foi determinada pelo método de Lowry (LOWRY et al., 1951), sumarizado a seguir:

Em $100 \mu \mathrm{l}$ de amostra, foi acrescentado $1 \mathrm{ml}$ de solução C (solução A: $\mathrm{Na}_{2} \mathrm{CO}_{3} 189$ mM; $\mathrm{NaOH} 100$ mM, Tartarato de $\mathrm{Na}$ e K 0,7 mM adicionada de solução B: $\mathrm{CuSO}_{4}$. 5 $\mathrm{H}_{2} \mathrm{O} 16$ mM, numa proporção de 50 volumes de solução A: 1 volume de solução B). Após 10 minutos de incubação a $37^{\circ} \mathrm{C}$, adicionou-se a solução de Folin Coiceareau $(75 \mu \mathrm{l})$. Após 30 minutos de incubação a $37^{\circ} \mathrm{C}$, a concentração de proteína foi avaliada por leitura em espectrofotômetro (750 $\mathrm{nm}$ ), utilizando-se uma curva padrão de calibração de albumina sérica bovina (BSA fração V) de 0,05 a $0,5 \mathrm{mg} / \mathrm{ml}$. Os valores de concentração proteica das amostras de frações de membrana foram aferidos nesta curva de calibração.

\section{c) Western blotting}

Amostras de proteínas totais de membranas foram submetidas a Western blotting para a quantificação das proteínas GLUT4 e receptor $\beta_{2}$-adrenérgico, que envolveu as seguintes etapas:

- "SDS-PAGE"

Foi utilizado o método desenvolvido por Laemmli e modificado por Garfin (GARFIN, 1990), que envolve um sistema descontínuo de dois géis contíguos: gel de empacotamento (stacking gel) e gel de separação (resolving gel) das amostras, que foram acrescidas de glicerol 15\%; tris 0,05 M; Bromofenol Blue 0,05\%; SDS 9\%, com 6\% de 2-mercaptoetanol 1:1, fervidas por 5 minutos e colocadas em gelo até o uso.

A eletroforese foi realizada em tampão Tris $\mathrm{HCl} 25$ mM, glicina $190 \mathrm{mM}$, SDS 10\%, EDTA 2 mM com voltagem constante para o gel de empacotamento (75 V) e corrente constante para o gel de separação (60 mA).

\section{- Transferência Eletroforética}

A transferência eletroforética para a membrana de nitrocelulose Hybond-ECL ${ }^{\circledR}$ (Amersham Biosciences, Buckinghamshire, UK) foi realizada sob corrente constante de $40 \mathrm{~mA}$, por 16 horas a $4{ }^{\circ} \mathrm{C}$, em tampão de transferência (Tris HCL 0,25 M, Glycine 1,9 M, água milliQ e metanol). 
A qualidade da transferência e o controle interno foram verificados corando-se o gel com azul brilhante de coomassie (TIMMONS; DUNBAR, 1990; TOWBIN; STAEHELIN; GORDON, 1979).

- "ECL-Enhanced Chemiluminescence"

Primeiramente foi feito o bloqueio inespecífico da membrana em leite desnatado ( $8 \%$, Molico ${ }^{\circledR}$-Nestlé) diluído em PBS $1 \mathrm{X}$ pH 7,2 [NaCl 0,8\%; $\mathrm{Na}_{2} \mathrm{HPO}_{4} \cdot\left(12 \mathrm{H}_{2} \mathrm{O}\right) 0,115 \% ; \mathrm{KCl}$ $0,02 \% ; \mathrm{KH}_{2} \mathrm{PO}_{4} 0,02 \%$ ] por 1 hora, sob agitação constante.

Após, incubou-se com anticorpo primário anti-GLUT-4 (07-1404 - Polyclonal antibody, Millipore, Temecula - CA) (1:4000) em PBS 1X (BSA 8\%) por 3 horas a $37^{\circ} \mathrm{C}$, sob agitação; ou overnight a $4{ }^{\circ} \mathrm{C}$, sob agitação constante, com o anticorpo $\beta_{2}$-adrenérgico [SC569 - $\beta_{2}$-AR (H-20), Rabbit Polyclonal IgG, Santa Cruz Biotechnology, Santa Cruz - CA] (1:500) em PBS 1X (BSA 1\%).

Posteriormente, a membrana foi incubada com anticorpo secundário (NA934 Amersham ECL Anti-rabbit IgG, GE Healthcare, Uppsala - SE) conjugado com enzima peroxidase-HRP (1:10000 e 1:5000, respectivamente para GLUT4 e para $\beta_{2}$-AR) em PBS $1 X+$ $0,1 \%$ Tween $+1 \%$ de leite desnatado por 1 hora, sob agitação a temperatura ambiente.

A reação da oxidação do luminol pela peroxidase tendo como substrato peróxido de hidrogênio, foi visualizada por meio de quimioluminescência (ECL - enhanced chemiluninescence) utilizando-se kit (ECL - Amersham Biosciences).

A membrana foi exposta a filme (Kodak X-Omat LS, Kodak Company, Rochester, NY), por um tempo variável de 1,5 a 5 minutos. Após esse período o filme foi revelado e fixado com solução reveladora e reforçadora GBX e solução fixadora e reforçadora GBX (Kodak Brasileira, São Paulo, BR), respectivamente.

\section{- Densitometria óptica}

A intensidade dos "blots" foi avaliada por densitometria óptica, utilizando-se o programa (imlD - Pharmacia Biotech, Uppsala, SW) e o resultado numérico foi expresso em unidades arbitrárias (UA), total ou por grama de tecido, em relação à quantidade de proteína que foi aplicada para a eletroforese, e considerando 100 o valor obtido em cada experimento para a amostra de W (estudo 1) ou WS (estudo 2). 


\subsection{Determinação da concentração plasmática de ácidos graxos livres}

A dosagem de ácidos graxos livres foi feita pelo método de Chromý et al. (1977).

Em tubos de ensaio com tampa, foram pipetados $1 \mathrm{ml}$ de tampão fosfato $\left(2 \mathrm{KH}_{2} \mathrm{PO}_{4}\right.$ 0,033 M: $1 \mathrm{NaHPO}_{4}$ 0,033 M), $100 \mu \mathrm{l}$ de plasma e/ou padrão e $6 \mathrm{ml}$ de solução extratora (CHM - clorofórmio: heptano [v/v] e $2 \%$ de metanol). Os tubos foram agitados vigorosamente por 10 minutos, e após 15 minutos de repouso, centrifugados (377 g, 10 minutos). A parte superior do líquido foi removida, por sucção, e transferiu-se $4 \mathrm{ml}$ da fase inferior para outro tubo contendo 2 $\mathrm{ml}$ de Cobre-TEA $\left(\mathrm{Cu}\left(\mathrm{NO}_{3}\right)\right.$ 0,05 M; TEA 0,1 M; $\left.\mathrm{NaOH} 0,06 \mathrm{~N} ; \mathrm{NaCl} 8,3 \mathrm{M} ; \mathrm{pH} 8,1\right)$, e agitou por 20 minutos. Após, o tubo foi centrifugado ( $377 \mathrm{~g}, 20$ minutos) e transferiu-se $2 \mathrm{ml}$ da fase superior para tubo de leitura, acrescentando $0,5 \mathrm{ml}$ de solução DPC (reativo de cor Difenilcarbazida, difenilcarbazona, etanol e TEA). Após agitação em vórtex foi realizada a leitura em espectrofotômetro a $550 \mathrm{~nm}$. A quantificação da concentração foi feita com base em uma curva padrão feita com ácido palmítico.

\subsection{Medida de pressão caudal}

A pressão caudal foi medida em ratos acordados usando o pletismógrafo modelo LE 5001 PRESSURE METER (PANLAB - Technology for Bioresearch). Antes de medir a pressão inicial, os ratos foram submetidos, em 2 dias diferentes, ao sistema de aferição de pressão arterial para adaptação. Para a obtenção das medidas, os ratos foram aquecidos por 10 minutos $\left(35^{\circ} \mathrm{C}\right) \mathrm{e}$, após, foram medidos 10 valores de pressão caudal a partir dos quais se obteve uma média, sendo esse o valor usado como representativo de um animal. Aferiu-se a pressão caudal antes a após o tratamento com propranolol.

\subsection{Análise dos resultados}

Os resultados foram analisados através de análise de variância ANOVA de uma via, seguida pelo pós-teste de comparação (Newman-Keuls); ou ANOVA de duas vias, seguida pelo pós-teste de comparação (Bonferroni). Quando necessário foi feito o teste "t" para comparação de apenas dois grupos experimentais. Essas análises foram feitas com auxílio do programa computacional GraphPad Prism $^{\circledR}$, v. 3,02 (GraphPad, USA). 


\section{RESULTADOS}

Estudo 1

Primeiramente fizemos um estudo para analisar a expressão do GLUT4 nos animais Wistar (W), Wistar diabético (WD), Wistar-Kyoto (K), Wistar-Kyoto diabético (KD), SHR (S) e SHR diabético (SD). Este estudo foi feito para selecionarmos o melhor controle para o estudo 2.

A tabela 2 mostra o peso corporal e dos tecidos musculares sóleo e EDL, no dia da eutanásia (1 mês de diabetes no grupo WD, KD e SD), glicemia e insulinemia (no horário da eutanásia, $\sim 9$ hs), volume urinário e glicosúria (24 horas antes da eutanásia). Os SHR e WistarKyoto apresentaram peso corporal menor que os animais Wistar. O diabetes causou uma queda de peso nos grupos WD e KD, comparando com W e K, respectivamente, assim como causou uma diminuição no peso do tecido muscular esquelético EDL em WD. A glicemia foi maior nos grupos diabéticos, tendo um aumento muito maior no grupo WD. A concentração de insulina plasmática foi maior nos animais hipertensos quando comparado aos normotensos (Wistar e Wistar-Kyoto) e os grupos diabéticos apresentaram menor insulinemia que os grupos não diabéticos. O volume urinário e a glicosúria foram maiores em animais diabéticos do que nos animais não diabéticos. 


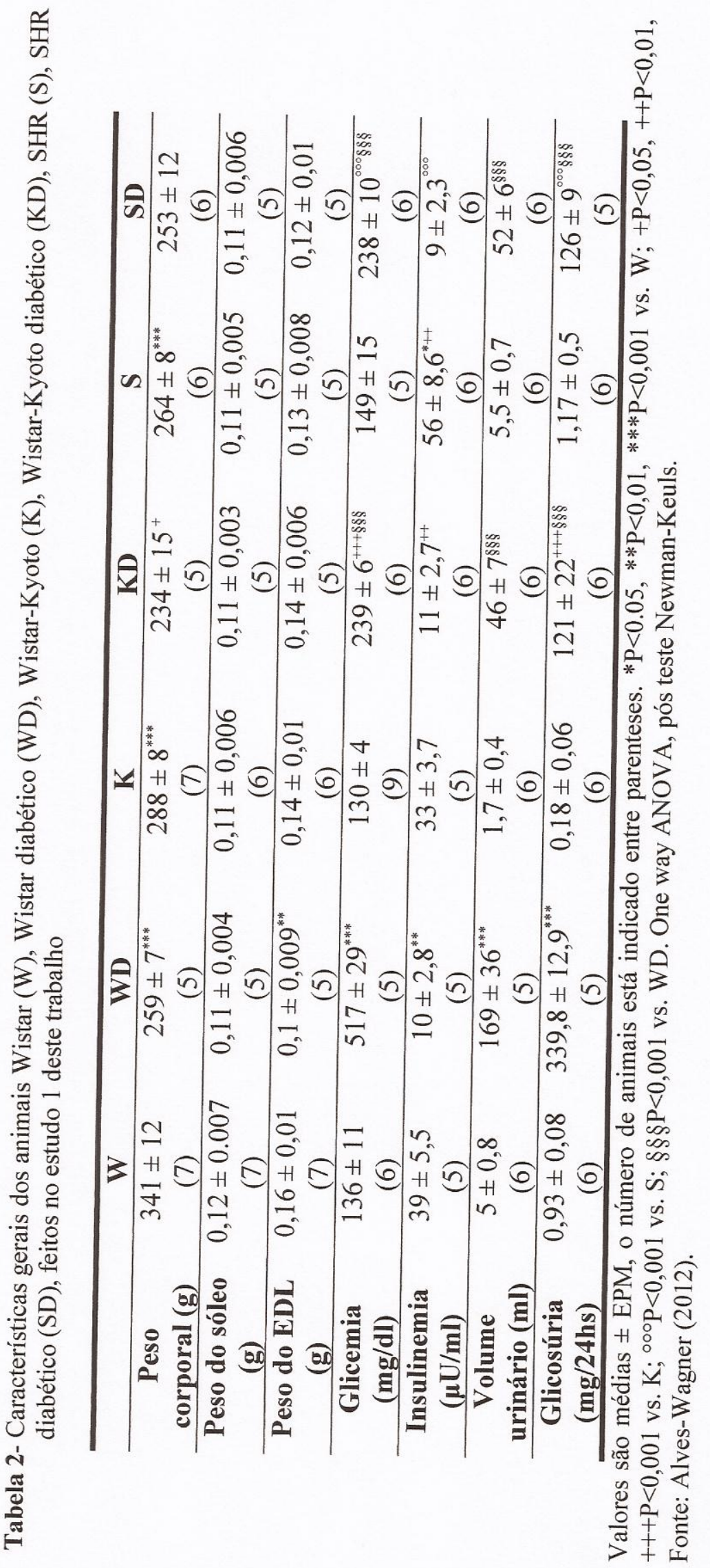




\section{1 mRNA Slc2a4}

As figuras 2 e 3 mostram a quantidade de mRNA Slc2a4 presente no músculo esquelético sóleo e EDL, respectivamente. No sóleo, os animais dos grupos $\mathrm{K}$ e $\mathrm{S}$ apresentaram um aumento do mRNA (vs. W); e o diabetes, reduziu o conteúdo de mRNA em WD (vs. W) e SD (vs. S). No EDL, o diabetes reduziu a expressão de Slc2a4 apenas WD (vs. W); ainda, tanto S como SD apresentaram maior conteúdo de Slc2a4 no EDL (vs. W e K diabéticos ou não).

Figura 2- Expressão do mRNA Slc2a4 no músculo esquelético sóleo dos animais dos grupos Wistar (W), Wistar diabético (WD), Wistar-Kyoto (K), Wistar-Kyoto diabético (KD), SHR (S), SHR diabético (SD). Quantidade de mRNA em UA, unidades arbitrárias
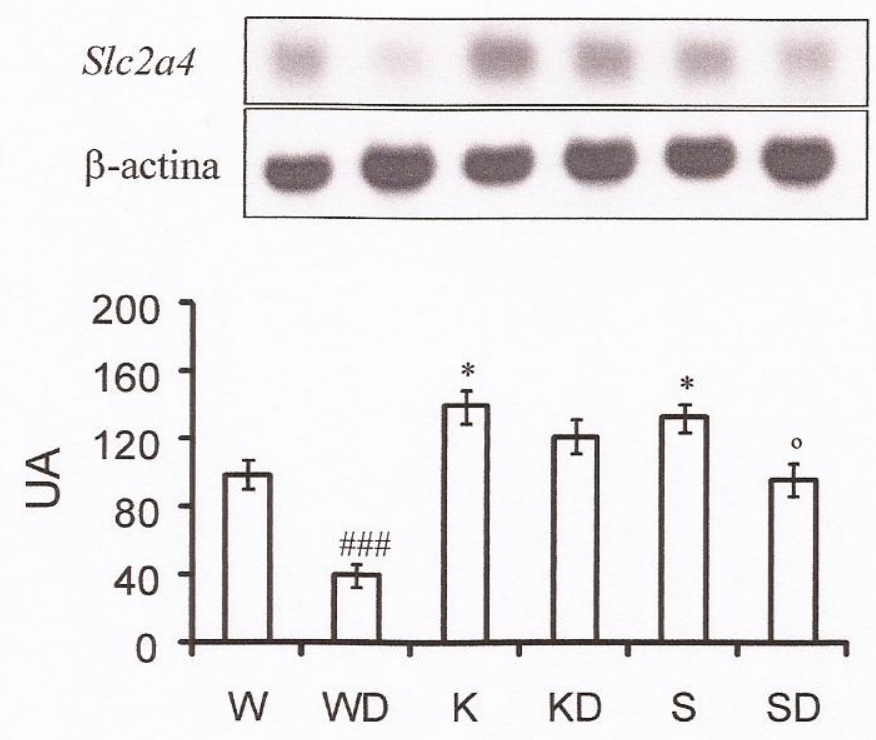

Valores são média \pm EPM de $7(\mathrm{~W}), 5(\mathrm{WD})$ a $6(\mathrm{~K}, \mathrm{KD}, \mathrm{S}$ e SD) animais por grupo. \#\#\#P<0.001 vs. demais grupos, ${ }^{*} \mathrm{P}<0,05$ vs. $\mathrm{W},{ }^{\circ} \mathrm{P}<0,05$ vs. S. One way ANOVA, pós teste Newman-Keuls.

Fonte: Alves-Wagner (2012). 
Figura 3- Expressão do mRNA Slc2a4 no músculo esquelético EDL dos animais dos grupos Wistar (W), Wistar diabético (WD), Wistar-Kyoto (K), Wistar-Kyoto diabético (KD), SHR (S), SHR diabético (SD). Quantidade de mRNA em UA, unidades arbitrárias
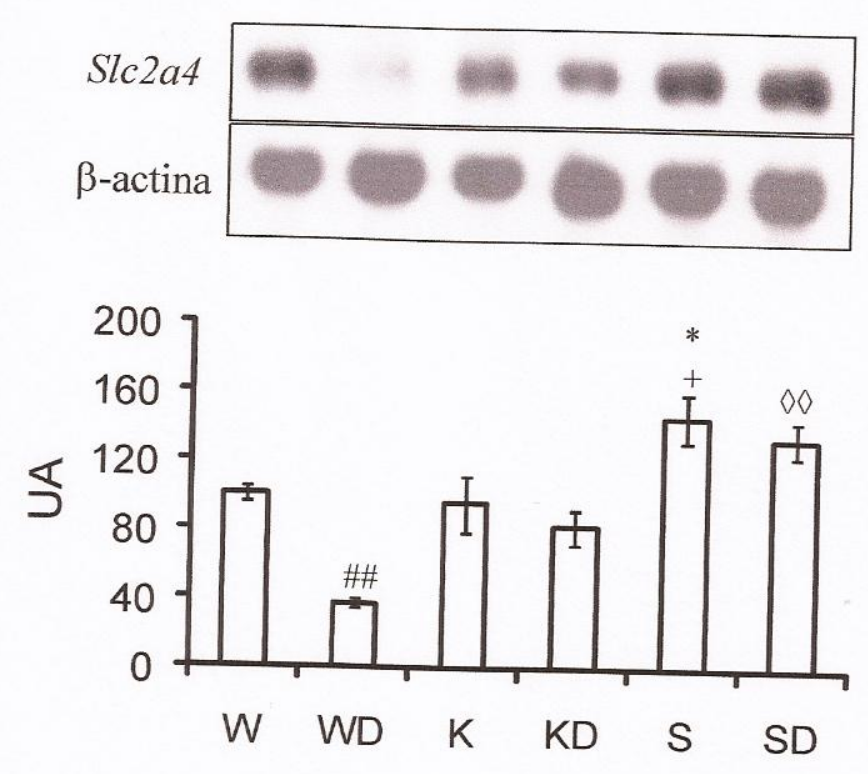

Valores são média \pm EPM de 7 (W), 5 (WD) a $6(\mathrm{~K}, \mathrm{KD}, \mathrm{S}$ e $\mathrm{SD})$ animais por grupo. \#\#P<0.01 vs. demais grupos, ${ }^{*} \mathrm{P}<0,05$ vs. $\mathrm{W},+\mathrm{P}<0,05$ vs. $\mathrm{K}, \diamond \diamond \mathrm{P}<0,01$ vs. KD. One way ANOVA, pós teste Newman-
Keuls. Fonte: Alves-Wagner (2012).

\subsection{Proteína GLUT4}

As figuras 4 e 5 mostram a quantidade de proteína GLUT4 total no tecido muscular esquelético sóleo e EDL, respectivamente. O diabetes reduziu o conteúdo de proteína tanto no sóleo quanto no EDL dos animais do grupo WD, e apenas no EDL de animais hipertensos (SD vs. S e KD). 
Figura 4- Expressão da proteína GLUT4 total no músculo esquelético sóleo dos animais dos grupos Wistar (W), Wistar diabético (WD), Wistar-Kyoto (K), Wistar-Kyoto diabético (KD), SHR (S), SHR diabético (SD). Quantidade de proteína em UA, unidades arbitrárias. Controle interno refere-se a faixa de 40-60 kDa do gel corado pós transferência com azul brilhante de coomassie.
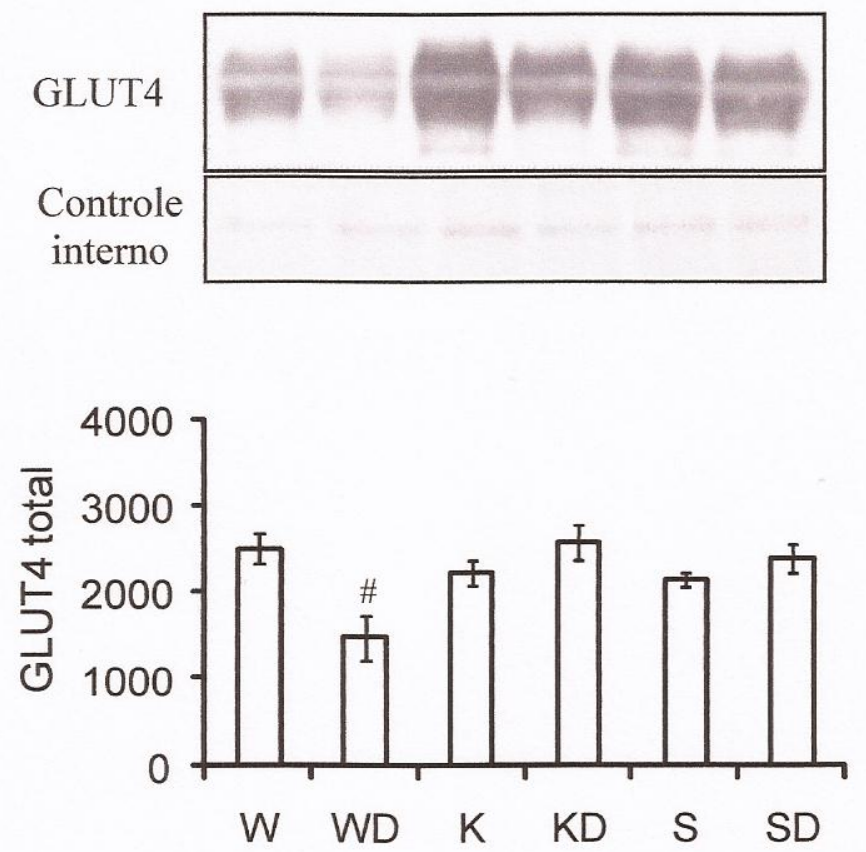

Valores são média \pm EPM de $7(\mathrm{~W})$ e $5(\mathrm{WD}, \mathrm{K}, \mathrm{KD}, \mathrm{S}$ e $\mathrm{SD})$ animais por grupo. \#P<0,05 vs. demais grupos. One way ANOVA, pós teste Newman-Keuls.

Fonte: Alves-Wagner (2012). 
Figura 5: Expressão da proteína GLUT4 total no músculo esquelético EDL dos animais dos grupos Wistar (W), Wistar diabético (WD), Wistar-Kyoto (K), Wistar-Kyoto diabético (KD), SHR (S), SHR diabético (SD). Quantidade de proteína em UA, unidades arbitrárias. Controle interno refere-se a faixa de $40-60 \mathrm{kDa}$ do gel corado pós transferência com azul brilhante de
coomassie.
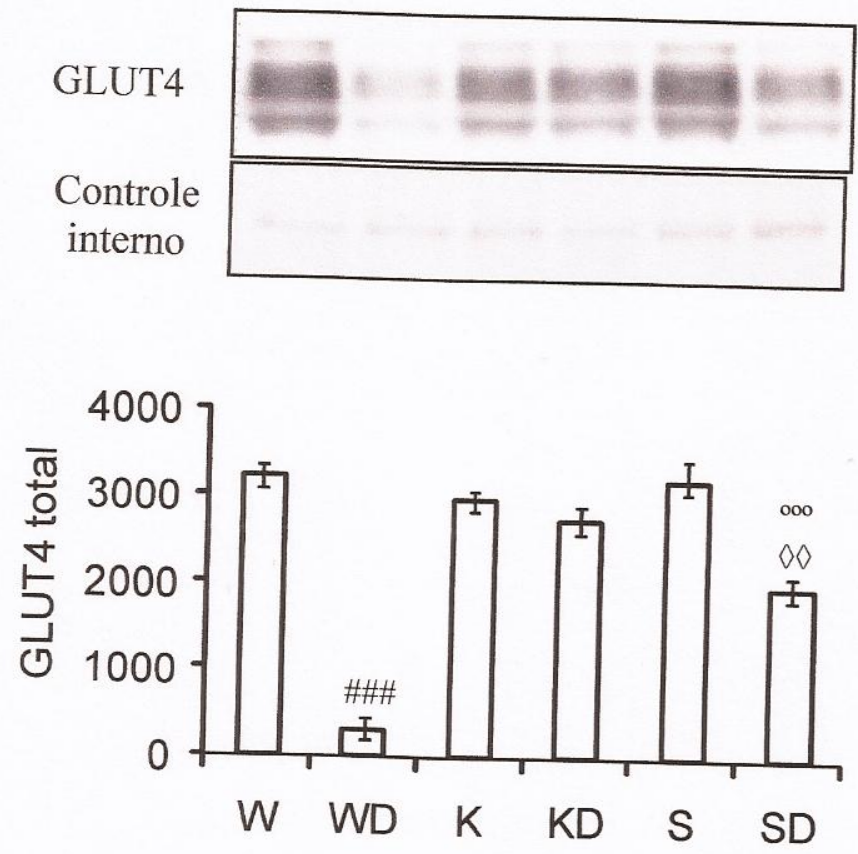

Valores são média \pm EPM de $6(\mathrm{~W})$ e $5(\mathrm{WD}, \mathrm{K}, \mathrm{KD}, \mathrm{S}$ e $\mathrm{SD})$ animais por grupo. \#\#\#P<0,001 vs. demais

grupos; ${ }^{\circ 0} \mathrm{P}<0,001$ vs. $\mathrm{S} ; \diamond \diamond \mathrm{P}<0,01$ vs. KD. One way ANOVA, pós teste Newman-Keuls.
Fonte: Alves-Wagner (2012).

Com base na resposta diferenciada dos animais Wistar-Kyoto diabéticos, que não reduziram a expressão de Slc2a4/GLUT4 conforme extensivamente demonstrado na literatura, passamos a utilizar ratos diabéticos normotensos Wistar como controle dos diabéticos SHR, tratados ou não com insulina e/ou propranolol por 7 dias. 
Estudo 2

\subsection{Peso corporal, volume urinário e glicosúria}

A tabela 3 mostra o peso corporal, volume urinário e glicosúria antes (inicial) e após o tratamento de 7 dias (final) dos animais normotensos e hipertensos tratados com salina, insulina, propranolol e propranolol+insulina.

Os animais diabéticos, normotensos e hipertensos, tratados com insulina (na presença ou ausência do propranolol) tiveram um aumento significativo do peso corporal e uma diminuição significativa do volume urinário e da glicosúria em relação aos valores iniciais (antes do tratamento). $\mathrm{O}$ tratamento com propranolol não alterou esses fatores analisados. 


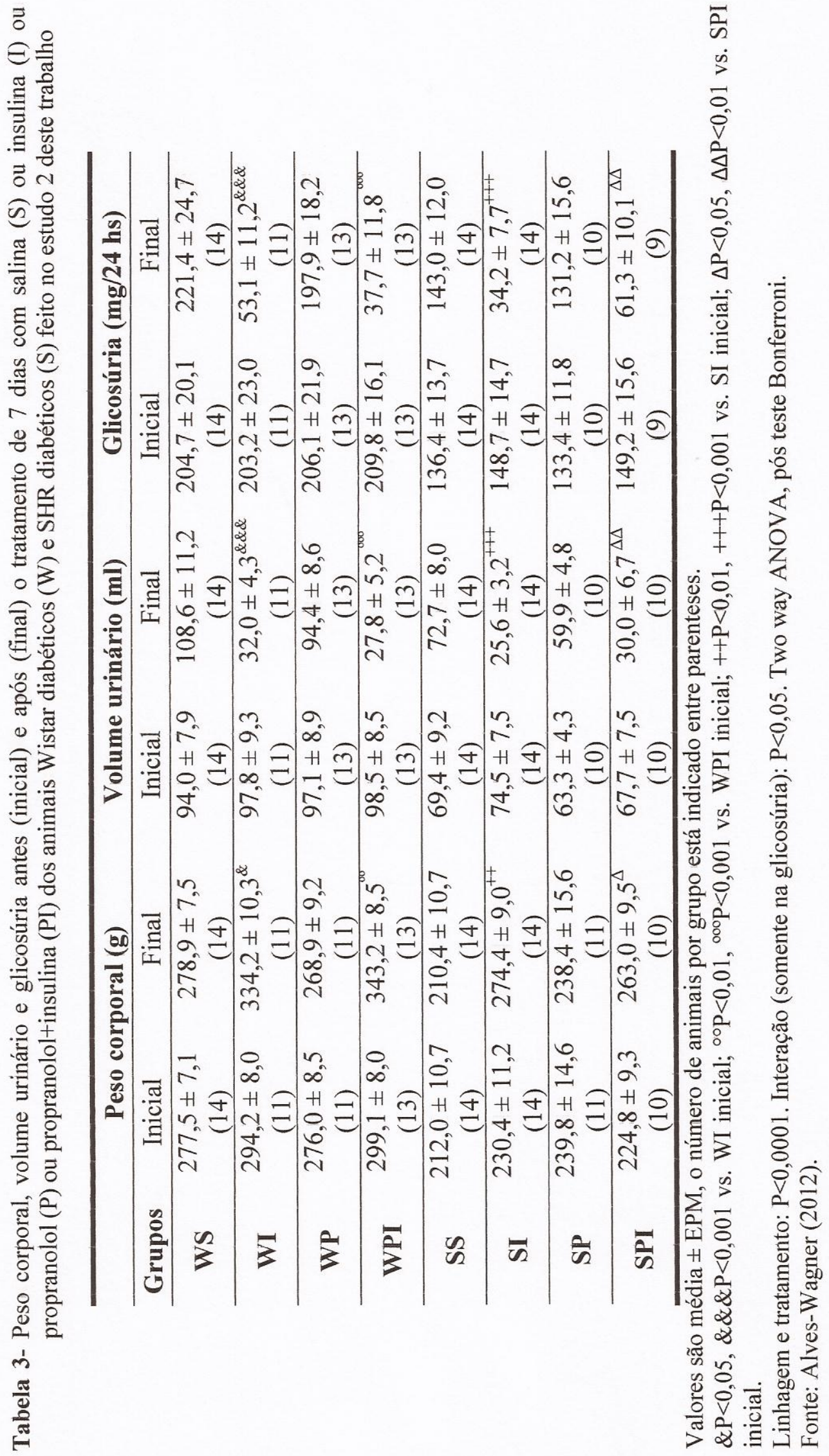




\subsection{Glicemia}

A glicemia foi medida em sangue obtido da veia cava inferior na hora da eutanásia. Os animais diabéticos, normotensos e hipertensos, tratados com insulina, na ausência e na presença de propranolol, tiveram uma redução significativa na glicemia (vs. WS e SS, respectivamente).

Figura 6- Glicemia dos animais dos grupos Wistar diabéticos tratados com salina (WS), insulina (WI), propranolol (WP) e propranolol + insulina (WPI) e SHR diabéticos tratados com salina (SS), insulina (SI), propranolol (SP) e propranolol + insulina (SPI)

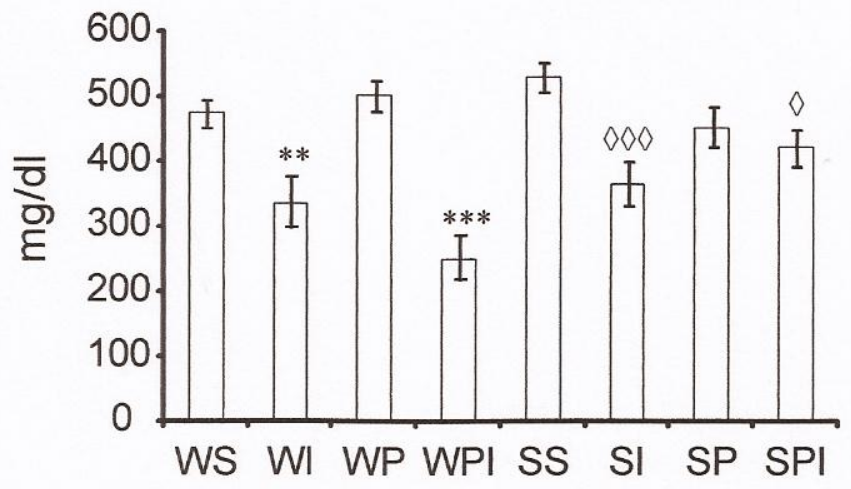

Valores são média $\pm \mathrm{EPM}$ de $7-10$ animais por grupo. ${ }^{* *} \mathrm{P}<0,01, * * * \mathrm{P}<0,001$ vs. WS; $\diamond \mathrm{P}<0,05$, $\diamond \diamond \diamond \mathrm{P}<0,001$ vs. SS.

Linhagem: $\mathrm{P}<0,05$; tratamento: $\mathrm{P}<0,0001$ e interação: $\mathrm{P}<0,01$. Two way ANOVA, pós teste Bonferroni. Fonte: Alves-Wagner (2012).

\subsection{Insulinemia}

A concentração de insulina plasmática dos animais diabéticos tratados com insulina (na presença ou ausência do propranolol) aumentou significativamente, tanto nos normotensos quanto nos hipertensos, conforme esperado.

Destaca-se que, comparando-se apenas animais não tratados com insulina (ANOVA de uma via, pós teste Newman-Keuls), observou-se que os animais hipertensos tiveram maior concentração de insulina que os animais normotensos (WS e WP) $(\mathrm{P}<0,01)$. Adicionalmente, observou-se que o tratamento com propranolol nos hipertensos aumentou ainda mais a concentração plasmática de insulina (SS vs. SP, $\mathrm{P}<0,01$ ). Estas comparações não são mostrada na figura 7. 
Figura 7: Concentração de insulina plasmática dos animais dos grupos Wistar diabéticos tratados com salina (WS), insulina (WI), propranolol (WP) e propranolol + insulina (WPI) e SHR diabéticos tratados com salina (SS), insulina (SI), propranolol (SP) e propranolol + insulina (SPI)

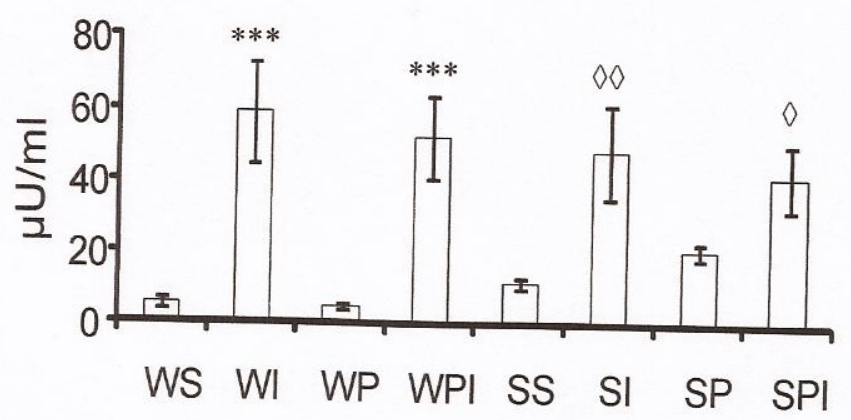

Valores são média \pm EPM de 4-8 animais por grupo. $* * * \mathrm{P}<0,001$ vs. WS; $\diamond \mathrm{P}<0,05, \diamond \diamond \mathrm{P}<0,01$ vs. SS Tratamento: $\mathrm{P}<0,0001$. Two way ANOVA, pós teste Bonferroni.

Fonte: Alves-Wagner (2012).

\section{6 Ácidos graxos livres (AGL)}

A concentração de AGL foi avaliada do plasma de sangue obtido no momento da eutanásia. Os animais normotensos e hipertensos tratados com insulina (na presença ou ausência de propranolol) tiveram um aumento na concentração de AGL comparados aos animais tratados com salina. Analisando os grupos SS e SP por teste "t", observou-se redução na concentração de AGL nos animais tratados com propranolol ( $\mathrm{P}=0.0127)$, comparação não mostrada na figura 8 . 
Figura 8- Concentração de ácidos graxos livres dos animais dos grupos Wistar diabéticos tratados com salina (WS), insulina (WI), propranolol (WP) e propranolol + insulina (WPI) e SHR diabéticos tratados com salina (SS), insulina (SI), propranolol (SP) e propranolol + insulina (SPI)

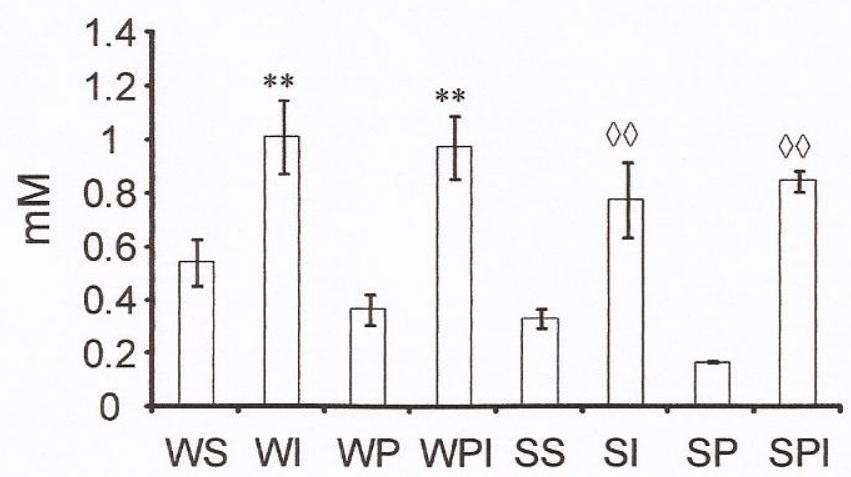

Valores são média $\pm \mathrm{EPM}$ de 4-6 animais por grupo. ${ }^{* * \mathrm{P}<0,01}$ vs. WS; $\diamond \diamond \mathrm{P}<0,01$ vs. SS. Linhagem: $\mathrm{P}<0,05$; tratamento: $\mathrm{P}<0,0001$. Two way ANOVA, pós teste Bonferroni.

Fonte: Alves-Wagner (2012).

\subsection{Pressão caudal}

A figura 9 mostra a medida da pressão caudal obtida antes e após o tratamento com propranolol por 7 dias, somente nos animais dos grupos Wistar diabético (WP) e SHR (SP) diabético. O tratamento com propranolol reduziu a pressão caudal nos animais hipertensos, não alterando a pressão dos animais normotensos. 
Figura 9- Pressão caudal obtida dos animais dos grupos Wistar diabéticos antes (W) e após o tratamento com propranolol, por 7 dias (WP) e SHR diabéticos antes (S) e após o tratamento com propranolol, por 7 dias (SP).

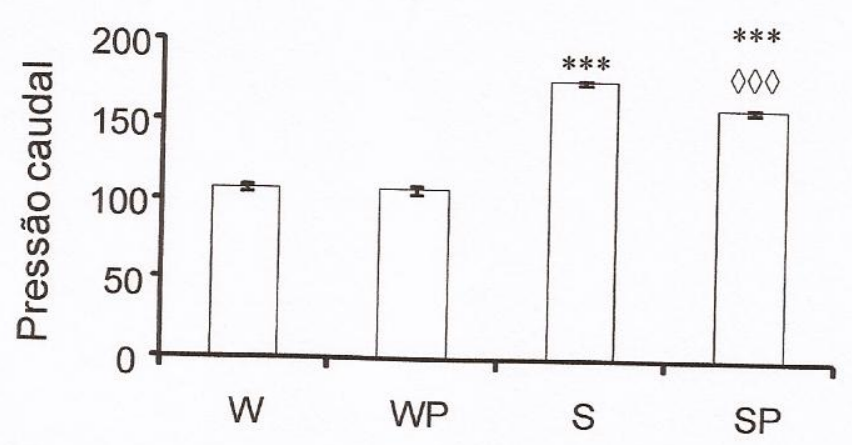

Valores são média \pm EPM de $13(\mathrm{~W}), 6$ (WP), 7 (S) e 5 (SP) animais por grupo. ***P<0,001 vs. W e WP; $\diamond 0 \diamond \mathrm{P}<0,001$ vs. S. One way ANOVA, pós teste Newman-Keuls.

Fonte: Alves-Wagner (2012).

\section{8 mRNA Slc2a4}

No sóleo (Fig. 10A), o tratamento com insulina, com ou sem propranolol, aumentou o conteúdo de Slc2a4 nos animais normotensos e hipertensos (vs. WS e SS, respectivamente).

Analisando os grupos WS e WP por teste "t", foi possível ver uma redução na expressão do mRNA dos animais tratados com propranolol $(\mathrm{P}=0,006)$. Além destes grupos, também comparamos (teste "t") os grupos SI e SPI quando observamos aumento na expressão do mRNA nos SPI $(\mathrm{P}=0,0004)$. Estas comparações não foram mostradas na figura $10 \mathrm{~A}$.

Diferentemente, no EDL, o tratamento com insulina reduziu e o tratamento com propranolol aumentou o mRNA Slc2a4 em ambas as linhagens (vs. grupo injetado somente com salina). Quando o tratamento foi associado (propranolol+insulina) o efeito da insulina (reduzir o mRNA) foi abolido (Fig. 10B).

Deve-se destacar que os animais hipertensos mostraram maior expressão do Slc2a4 que os respectivos animais normotensos, tanto no sóleo quanto no EDL. 
Figura 10- Expressão do mRNA Slc2a4 nos músculos esqueléticos sóleo (A) e EDL (B) dos animais Wistar diabéticos tratados com salina (WS), insulina (WI), propranolol (WP) e propranolol + insulina (WPI) e SHR diabéticos tratados com salina (SS), insulina (SI), propranolol (SP) e
propranolol + insulina (SPI)

A.
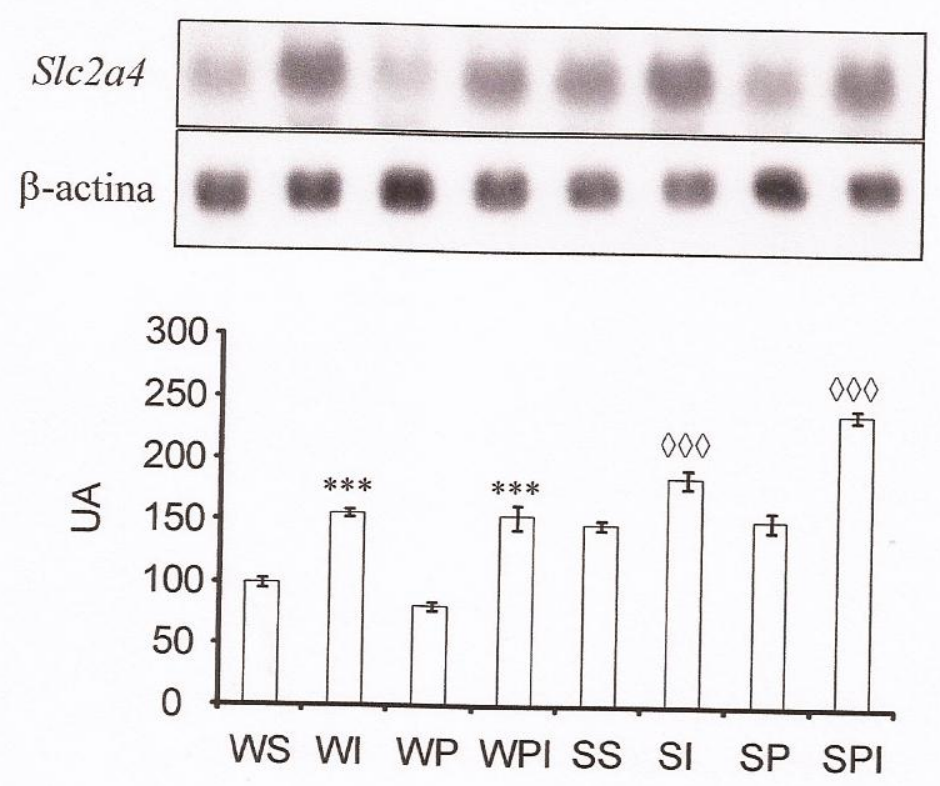

B.
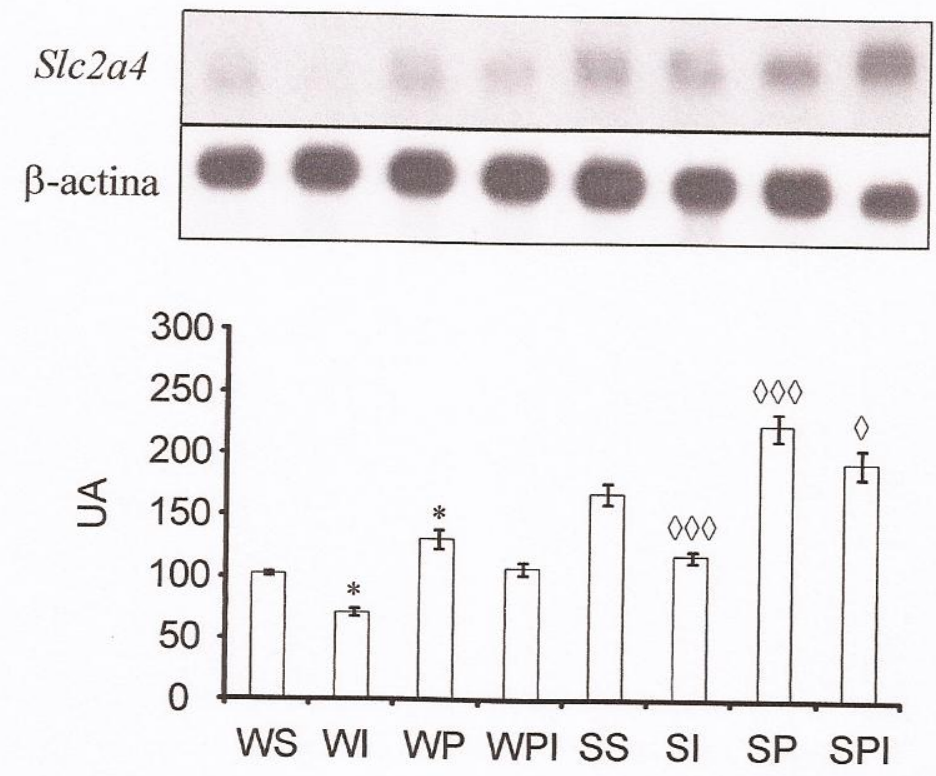

Valores são média $\pm \mathrm{EPM}$ de 5-8 animais por grupo. ${ }^{*} \mathrm{P}<0,05,{ }^{* * *} \mathrm{P}<0,001$ vs. WS; $\diamond \mathrm{P}<0,05, \diamond \diamond \diamond \mathrm{P}<0,001$ vs. SS.

Interação: $\mathrm{P}<0,001$ (A), $\mathrm{P}<0,05$ (B); linhagem e tratamento: $\mathrm{P}<0,0001$ (A e B). Two way ANOVA, pós teste Bonferroni.

Fonte: Alves-Wagner (2012). 


\subsection{Proteína GLUT4}

No músculo sóleo a insulina aumentou significativamente a proteína GLUT4 nos animais normotensos (vs. WS), associada ou não ao propranolol. Enquanto que nos animais hipertensos o tratamento com propranolol gerou esse aumento (vs. SS), independentemente da insulina (Fig. 11A).

No músculo EDL a expressão de GLUT4 aumentou nos animais normotensos tratados com propranolol+insulina (vs. WS), não ocorrendo esse aumento quando tratados isoladamente. Nos animais hipertensos, o propranolol aumentou a expressão de proteína GLUT4 quando comparado ao grupo tratado somente com salina (SS). Deve-se destacar que neste tecido os animais hipertensos tiveram maior expressão de proteína GLUT4 que os animais normotensos. 
Figura 11- Expressão de GLUT4/g de tecido nos músculos esqueléticos sóleo (A) e EDL (B) dos animais dos grupos Wistar diabéticos tratados com salina (WS), insulina (WI), propranolol (WP) e propranolol + insulina (WPI) e SHR diabéticos tratados com salina (SS), insulina (SI), propranolol (SP) e propranolol + insulina (SPI). Controle interno refere-se a faixa de 40-60 $\mathrm{kDa}$ do gel corado pós transferência com azul brilhante de coomassie.

A.
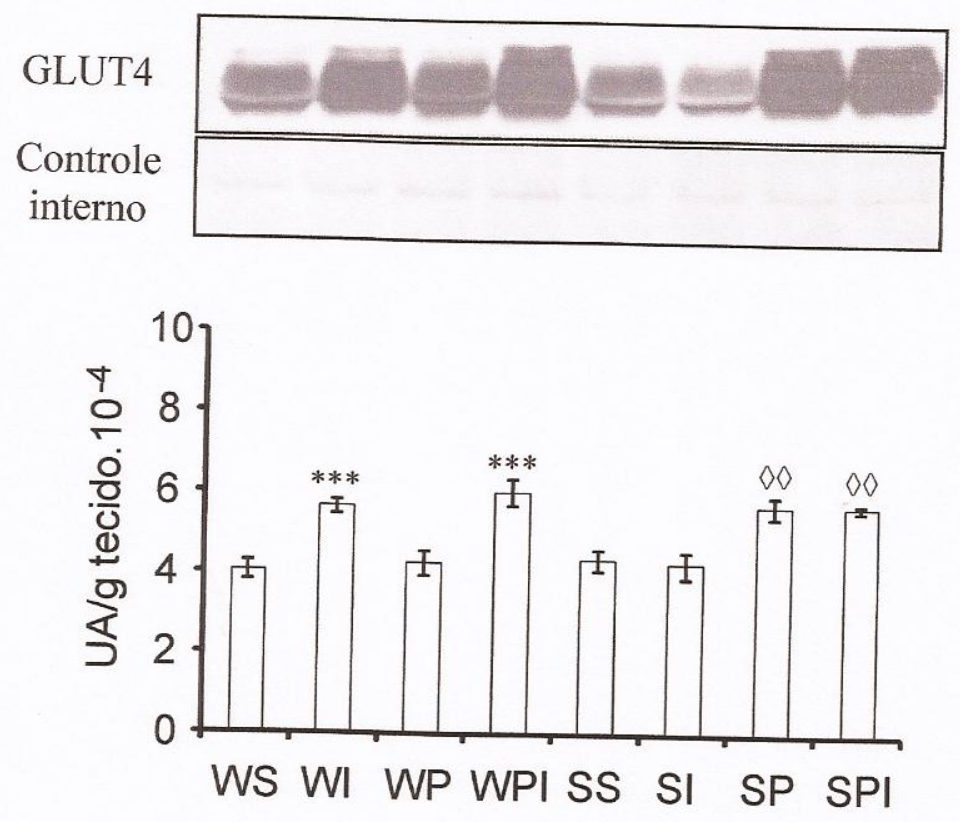

B.
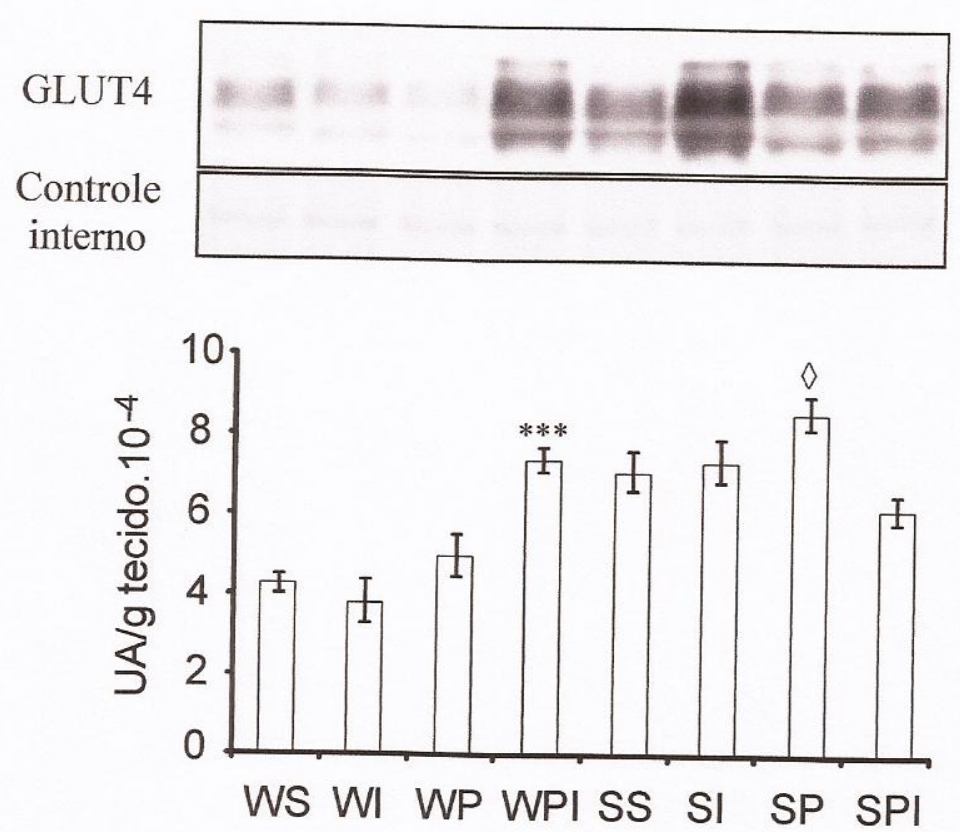

Valores são média $\pm \mathrm{EPM}$ de 5-10 animais por grupo. ${ }^{* * *} \mathrm{P}<0,001$ vs. WS; $\diamond \mathrm{P}<0,05, \diamond \diamond \mathrm{P}<0,01$ vs. SS. Interação: $\mathrm{P}<0,0001$ (A e B); tratamento: $\mathrm{P}<0,0001$ (A), $\mathrm{P}<0,01$ (B); linhagem: $\mathrm{P}<0,0001$ (B). Two way ANOVA, pós teste Bonferroni.

Fonte: Alves-Wagner (2012). 


\subsection{0 mRNA Tnfa}

No sóleo o tratamento com propranolol, tanto só quanto associado à insulina, reduziu a expressão do mRNA Tnfa, nos animais hipertensos diabéticos (vs. SS) (Fig. 12A).

Já no EDL, não houve diferença significativa entre os grupos (Fig. 12B). Porém, comparando os animais WS e WPI, teste " $t$ ", verificou-se que os animais do grupo WPI apresentaram menor expressão de Tnfa $(\mathrm{P}<0,05)$, comparação não mostrada na figura 12B. 
Figura 12- Expressão relativa de Tnfa/Gapdh em músculos esqueléticos sóleo (A) e EDL (B) dos animais dos grupos Wistar diabéticos tratados com salina (WS), insulina (WI), propranolol (WP) e propranolol + insulina (WPI) e SHR diabéticos tratados com salina (SS), insulina (SI), propranolol (SP) e propranolol + insulina (SPI).

A.
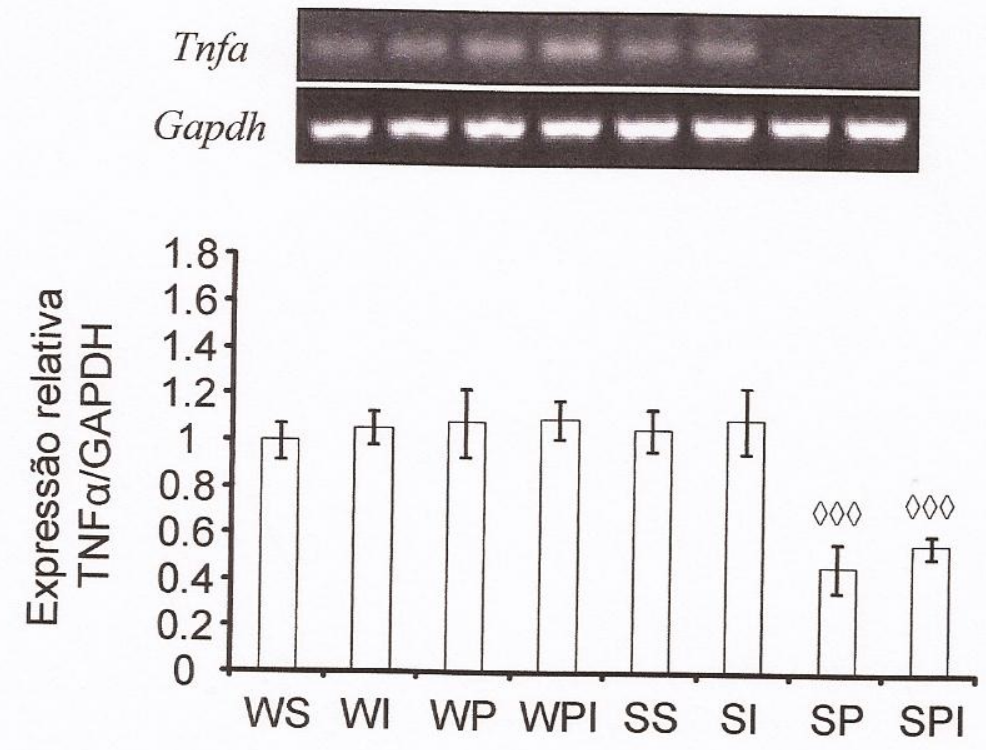

B.
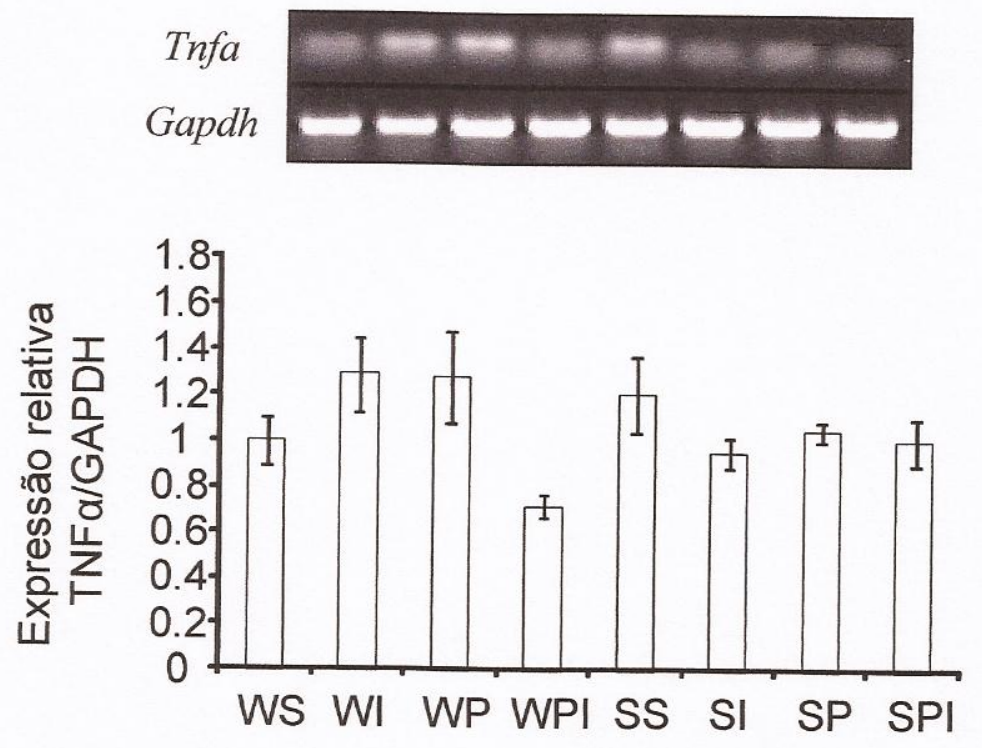

Valores são média \pm EPM de 5-7 animais por grupo. $\diamond 00 \mathrm{P}<0,001$ vs. SS.

Interação: $\mathrm{P}<0,01$ (A), $\mathrm{P}<0,05$ (B); tratamento: $\mathrm{P}<0,01$ (A); linhagem: $\mathrm{P}<0,001$ (A). Two way ANOVA, pós teste Bonferroni.

Fonte: Alves-Wagner (2012). 


\subsection{Receptores $\beta_{2}$-adrenérgicos}

A expressão dos receptores $\beta_{2}$-adrenérgicos foi maior em animais hipertensos que normotensos $(\mathrm{P}<0,01)$, no músculo esquelético sóleo (Fig. 13A). Neste mesmo tecido, os animais normotensos tratados com propranolol+insulina tiveram uma redução na quantidade de receptores quando comparados aos animais tratados somente com propranolol (WP vs. WPI). Quando analisado por teste " $\mathrm{t}$ " (WS vs. WP) os animais do grupo WP tiveram um aumento no número de receptores $(\mathrm{P}=0,0123)$, comparação não mostrada na figura $13 \mathrm{~A}$.

Não houve alteração, tanto entre as linhagens quanto nos tratamentos, no músculo esquelético EDL (Fig. 13B). 
Figura 13- Expressão de receptores $\beta_{2}$-adrenérgico em músculos esqueléticos sóleo (A) e EDL (B) dos animais dos grupos Wistar diabéticos tratados com salina (WS), insulina (WI), propranolol (WP) e propranolol + insulina (WPI) e SHR diabéticos tratados com salina (SS), insulina (SI), propranolol (SP) e propranolol + insulina (SPI). Controle interno refere-se a faixa de 40 $60 \mathrm{kDa}$ do gel corado pós transferência com azul brilhante de coomassie.

A.
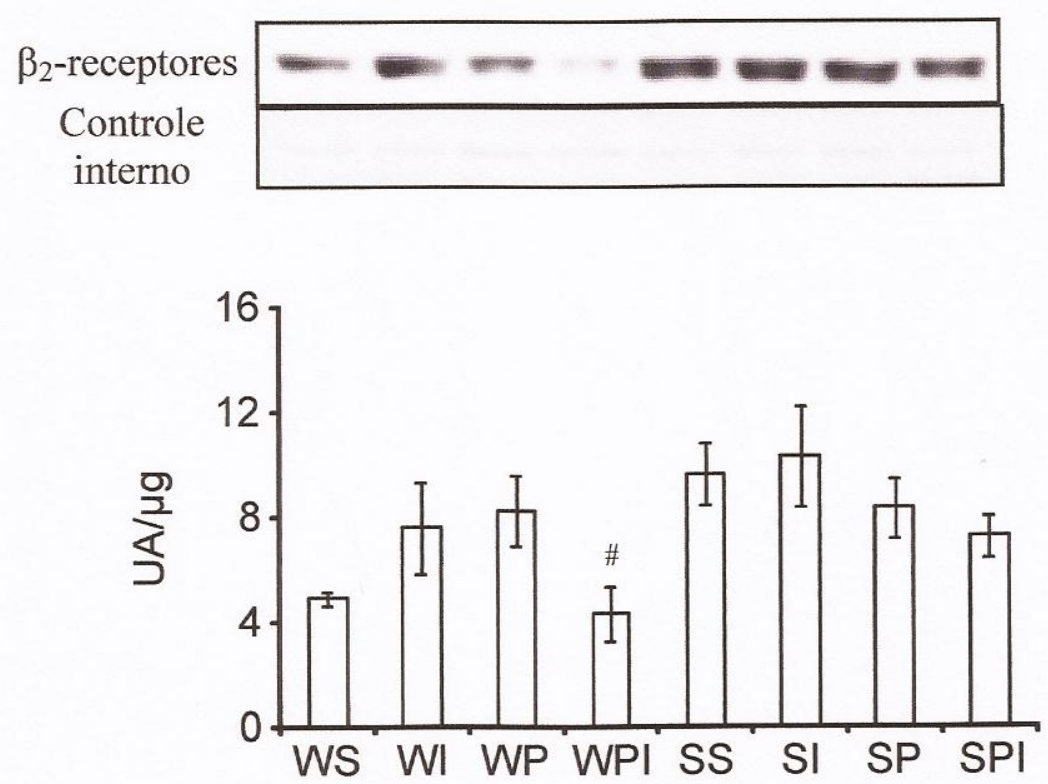

B.
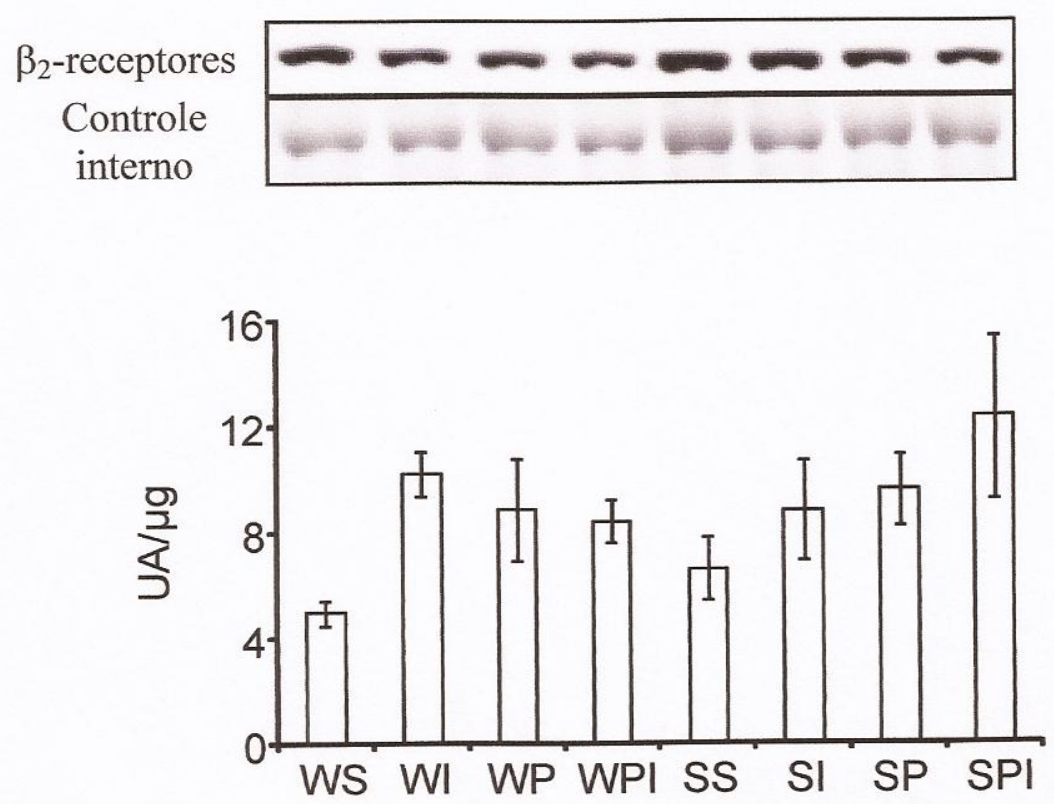

Valores são média \pm EPM de 4-8 animais por grupo. \#P<0,05 vs. WP.

Linhagem: $\mathrm{P}<0,01$ (A). Two way ANOVA, pós teste Bonferroni.

Fonte: Alves-Wagner (2012). 


\section{DISCUSSÃO}

A resistência à insulina está associada a inúmeras doenças crônicas como diabetes, obesidade e hipertensão arterial. Estudos que possam identificar mecanismos relacionados a alterações na ação e na sensibilidade à insulina nos tecidos periféricos são de extrema importância para a prevenção e tratamento dessas doenças.

Neste trabalho usamos o modelo de diabetes induzido por aloxana. A aloxana primeiramente inibe a glicoquinase (resposta rápida); e posteriormente induz a formação de espécies reativas de oxigênio (ROS), resultando na necrose seletiva de células beta pancreáticas (resposta mais lenta). Este modelo é importante para o entendimento dos mecanismos pelos quais ROS medeia a morte das células beta pancreáticas, que ocorre no diabetes tipo 1 e 2 (LENZEN, 2008). Este modelo representa um quadro de diabetes insulino privo, embora os animais apresentem uma secreção residual de insulina. Entretanto, esta secreção de insulina é insuficiente para promover o ganho de peso natural (veja evolução ponderal de animais Wistar na Tabela 1), embora seja capaz de impedir o desenvolvimento de um quadro cetótico com acidose metabólica. Portanto, este modelo também pode representar um diabetes tipo 2 que necessite de insulina para alcançar o controle glicêmico.

\section{Estudo 1}

O primeiro estudo nos permitiu identificar diferenças na expressão do Slc2a4 e do GLUT4 nos animais Wistar, Wistar diabético, Wistar-Kyoto, Wistar-Kyoto diabético, SHR e SHR diabético após 1 mês de evolução do diabetes. Este estudo foi realizado com base nas controvérsias sobre qual o melhor controle (Wistar ou Wistar-Kyoto) para animais SHR, um dos focos do presente estudo.

Estudos anteriores mostraram que os ratos Wistar-Kyoto possuem intolerância à glicose decorrente de resistência à insulina (KATAYAMA et al., 1997). De fato, prejuízo na atividade da via de sinalização da insulina também já foi demonstrado em ratos Wistar-Kyoto (KATAYAMA et al., 1997). Nossos resultados indicam que, em animais Wistar-Kyoto o efeito clássico de redução do Slc2a4/GLUT4 pelo diabetes (BERGER et al., 1989; OKAMOTO et al., 2011; SIVITZ et al., 1989) não foi observado no EDL, e no sóleo até aumentou o mRNA Slc2a4. Assim escolhemos ratos Wistar como controle do SHR já que ratos Wistar-Kyoto apresentam 
resistência à insulina (KATAYAMA et al., 1997) e alterações paradoxais na expressão gênica do Slc2a4/GLUT4 quando diabéticos. A justificativa de que Wistar-Kyoto é geneticamente semelhante ao SHR, e por isto deveria ser seu controle não se aplica no presente estudo, que visa contribuir para a fisiopatologia do diabetes, a qual sofre importante modulação de fatores genéticos distintamente expressos na população.

Além de nosso trabalho ter utilizado o Wistar como controle do SHR, outros trabalhos defendem essa comparação (Wistar e SHR), já que quando comparados a ratos Wistar, os ratos Wistar-Kyoto possuem alterações tanto no sistema cardiovascular (AIELLO et al., 2004), quanto na homeostase glicêmica (KATAYAMA et al., 1997).

O SHR é um animal que apresenta resistência à insulina, já tendo sido descrito: menor captação de glicose pelo adipócito (REAVEN et al., 1989), menor fosforilação em tirosina no receptor de insulina (IR) e no substrato do receptor de insulina (IRS1) em músculo (ZECCHIN et al., 2003), menor translocação do GLUT4 no tecido adiposo (CHIAPPE DE CINGOLANI; CALDIZ, 2004) e maior acúmulo lipídico em fígado e músculo (RODRÍGUEZ et al., 2008). Nossos resultados mostram que a resistência à insulina de SHR, embora não seja suficiente para alterar a glicemia basal, é capaz de induzir significativa hiperinsulinemia, um potente marcador de resistência à insulina.

Os ratos hipertensos (SHR) mostraram maior expressão do mRNA Slc2a4 no sóleo e no EDL, o que não se refletiu na proteína GLUT4. Resultados semelhantes (aumento do mRNA sem alteração da proteína) já foram observados por Katayama et al. (KATAYAMA et al., 1997). Estes dados indicam a ocorrência de alterações pós-transcricionais, que impedem uma regulação paralela entre mRNA e proteína GLUT4, e sugerem que, redução da proteína GLUT4 não esteja participando da resistência à insulina, pelo menos nesta fase de desenvolvimento.

O diabetes, conforme já foi descrito (MORA; PESSIN, 2000), reduz a expressão do Slc2a4 e da proteína GLUT4 nos animais normotensos Wistar, tanto no músculo sóleo quanto no EDL. Em relação à proteína GLUT4, já foi demonstrado que o efeito do diabetes está relacionado à hiperglicemia per se (glicotoxicidade), já que redução desta hiperglicemia com florizina é capaz de restaurar o conteúdo do GLUT4 e/ou a captação de glicose no diabetes (DIMITRAKOUDIS et al., 1992; NAPOLI; HIRSHMAN; HORTON, 1995).

No presente estudo, em SHR, embora o diabetes tenha reduzido a quantidade do mRNA Slc2a4, não houve redução na proteína GLUT4 em músculo oxidativo (sóleo), o que deve evitar 
um prejuízo maior na homeostasia glicêmica desses animais. Diferentemente, no EDL de SHR diabéticos, a expressão do mRNA Slc2a4 não alterou (vs. S), mas houve uma redução da proteína GLUT4, que ainda permaneceu maior do que o observado no grupo WD. Estas variações discrepantes entre mRNA e proteína indicam a ocorrência de regulação póstranscricional, o que é frequentemente observado neste gene. Nosso grupo já observou discrepâncias entre mRNA e proteína (Slc2a4/GLUT4) em gastrocnêmio de ratos obesos resistentes à insulina (SERAPHIM et al., 2007) e em sóleo e EDL de ratos jejuados (ALVESWAGNER et al., 2009), e em ambas as situações foi demonstrada a ocorrência de alterações no tamanho da cauda poli(A) dos mRNAs, explicando alteração na eficiência de tradução. Como alteração de tamanho de cauda poli(A) reflete-se em alteração do tamanho do transcrito, e consequentemente da migração do transcrito na eletroforese, a técnica de Northern blotting é capaz de indicar essas alterações, e por isso foi escolhida no presente estudo.

Sabe-se que humanos portadores de diabetes podem desenvolver neuropatia autonômica, reduzindo o tônus simpático em vários territórios do organismo (FERRARI; WEIDMANN, 1990; SCARPINI et al., 1993; VINIK et al., 2003). Em ratos, já foi demonstrado que o diabetes reduz o tônus simpático no músculo cardíaco, tecido adiposo marrom e pâncreas (YOSHIDA et al., 1985) e na glândula salivar de animais normotensos e hipertensos (SABINO-SILVA et al., 2010). Portanto, é possível que a diminuição da atividade simpática gerada pelo diabetes possa estar envolvida na redução da expressão do Slc2a4 e GLUT4, principalmente em situações de hiperatividade simpática, como observado em sóleo e EDL, respectivamente, de SHR.

\section{Estudo 2}

No segundo estudo, buscamos demonstrar a participação da atividade simpática $\beta$ adrenérgica na regulação da expressão do Slc2a4 e GLUT4, utilizando a ferramenta de bloqueio do sistema com propranolol.

Os animais diabéticos (W e SHR), quando tratados com insulina (7 dias), aumentaram significativamente o peso corporal, pois a insulina é um potente anabolizante, estimulando a síntese de glicogênio, proteína e gordura, o que se reflete em ganho de peso. Alguns autores demonstraram que este efeito da insulina é, sobretudo, marcante sobre o tecido adiposo epididimal, retroperitonial e subcutâneo, aumentando o peso dos ratos tratados (SALANS; ZARNOWSKI; SEGAL, 1972). 
Em relação ao controle metabólico, conforme esperado, o tratamento com insulina diminuiu significativamente a glicemia dos animais diabéticos (W e SHR), embora não tenha normalizado, e isto se refletiu em diminuição da glicosúria. Vale ressaltar que a última dose de insulina foi injetada às 17 horas do dia anterior, ou seja, no dia da eutanásia os animais não receberam injeção, por isso as glicemias devem estar mais altas do que o normalmente observado durante o tratamento. Entretanto, conforme desejado, a insulinoterapia induziu uma importante melhora no quadro diabético.

É importante comentar que a glicosúria observada nos animais diabéticos não tratados foi significativamente menor nos animais $\mathrm{SHR}$ ( $\mathrm{P}<0,01$ vs. Wistar) (comparação não mostrada na Tabela 3). Este dado poderia, a princípio, ser interpretado como se o grau de diabetes fosse bastante distinto entre as duas linhagens. Entretanto, destaca-se que, pareados pela idade, os animais SHR apresentam clara redução na massa corporal, de forma que, se a glicosúria (o mesmo vale para o volume urinário) for analisada relativamente ao peso corporal, o valor encontrado é semelhante em Wistar e SHR, $70 \mathrm{mg}$ de glicose em 24 horas por $100 \mathrm{~g}$ de peso corporal (dado não mostrado). Os valores de glicemia confirmaram grau de diabetes semelhante entre Wistar e SHR não tratados.

O tratamento com insulina também foi capaz de aumentar os níveis de ácidos graxos livres (AGL) em todas as condições experimentais. O aumento de AGL tem sido regularmente associado, entre outras situações, à condição de resistência à insulina (SAMUEL; PETERSEN; SHULMAN, 2010) ou de importante deficiência de insulina (SZTALRYD; KRAEMER, 1995). No presente estudo, o aparente paradoxal aumento de AGL em resposta a insulinoterapia pode decorrer do fato de os diabéticos terem esgotado massa adiposa ao ponto de terem restrita sua capacidade lipolítica; ou ainda do fato de o tratamento com insulina induzindo hiperinsulinemia, ter causado resistência à insulina, conforme recentemente demonstrado (OKAMOTO et al., 2011). Além disso, estudos in vitro mostraram que células adiposas, tratadas com insulina, desenvolvem uma super sensibilização adrenérgica, aumentando a produção de AMPc, devido a uma inibição da internalização dos receptores $\beta_{2}$-adrenérgicos (HUPFELD; DALLES; OLEFSKY, 2003). Assim, seria possível que nos animais tratados com insulina o aumento de AMPc ativaria a PKA, que no tecido adiposo fosforila e ativa a lipase hormônio sensível, ativando a lipólise, e elevando a concentração plasmática de AGL. 
Nos animais hipertensos diabéticos tratados com propranolol, foi encontrada uma redução na concentração de AGL (comparação não mostrada na figura 8). Conforme já comentado acima, a atividade adrenérgica estimula lipólise (STRALFORS; BJORGELL; BELFRAGE, 1984), aumentando AGL plasmáticos, e, portanto, era esperado que o bloqueio com propranolol reduzisse ácidos graxos livres, o que parece ter sido mais evidente em animais hipertensos, talvez por sua alta atividade simpática.

O tratamento com propranolol não alterou a pressão arterial de ratos Wistar, porém, como esperado, reduziu nos animais hipertensos (TAKEDA et al., 1979; TAKEDA; BUNAG, 1980), mostrando que o tratamento foi eficiente. Sabe-se que o bloqueio $\beta$-adrenérgico diminui a pressão em humanos e em animais hipertensos, por causar queda do débito cardíaco e perda de sódio e água pelo túbulo renal (SMITS; STRUYKER-BOUDIER, 1982). Já foi demonstrado que o aumento da pressão em resposta a adrenalina e angiotensina II é reduzido em SHR tratados com propranolol (KUBOTA; YAMADA, 1984). Além disso, a literatura indica que o propranolol reduz a síntese de noradrenalina (ELAYAN; KENNEDY; ZIEGLER, 1992), reduzindo o tônus simpático. Portanto, pelo descrito acima, compreende-se que os animais tratados com propranolol tiveram uma redução na atividade $\beta$-adrenérgica.

No sóleo, o mRNA Slc2a4 aumentou nos animais diabéticos tratados com insulina, tanto em normotensos como hipertensos. O resultado em animais Wistar está de acordo com o descrito na literatura, mostrando que o tratamento de ratos diabéticos com insulina aumenta o GLUT4 em sóleo e músculo cardíaco (RICHARDSON et al.,1991), assim como em tecido adiposo (SIVITZ et al., 1992). Em animais SHR diabéticos, que já mostravam mRNA Slc2a4 aumentado (em relação a Wistar diabético), o tratamento com insulina foi capaz de induzir um aumento adicional neste mRNA.

No sóleo, o propranolol causou diminuição na expressão de Slc2a4 nos animais diabéticos normotensos (comparação não mostrada na figura 10A). Esta regulação já foi descrita em sóleo de animais normotensos não diabéticos (ALVES-WAGNER et al., 2009), e reforça a importância do sistema $\beta$-adrenérgico em manter a expressão do Slc2a4 no músculo esquelético. Porém, o propranolol não alterou o Slc2a4 no sóleo de SHR diabético. A ausência de efeito do propranolol na expressão do transportador em SHR diabético pode estar relacionada ao fato de que: 1) estes animais apresentam hiperatividade simpática, de forma que mesmo tratados com 
propranolol, a atividade $\beta$-adrenérgica permanece maior que a de ratos Wistar-diabéticos; e 2) outros componentes do sistema nervoso simpático permaneceram hiperativos.

O tratamento associado de propranolol e insulina reverteu o efeito do propranolol em sóleo de normotensos diabéticos, indicando um efeito preponderante da insulina. Curiosamente, em SHR, a associação propranolol/insulina proporcionou expressão de mRNA Slc2a4 até mais elevados do que os observados em hipertensos diabéticos tratados apenas com insulina, contrariando o efeito inibidor do propranolol claramente observado em animais normotensos. Já foi documentado que a insulina aumenta a atividade simpática (FERRARI; WEIDMANN, 1990), portanto a insulina pode ter gerado um aumento da atividade simpática que superou o efeito do bloqueio com propranolol, preponderando o estímulo adrenérgico.

No EDL, de uma forma geral, as alterações do mRNA Slc2a4 mostraram um padrão inverso ao observado em sóleo. Tanto em normotensos como em hipertensos, a insulina diminuiu enquanto o propranolol, isoladamente, aumentou o mRNA Slc2a4. Em relação ao efeito da insulina em animais diabéticos, menor efeito da insulina no músculo esquelético branco, comparado ao tecido adiposo e ao sóleo, já foi descrito (RICHARDSON et al., 1991), indicando a presença de uma regulação tecido específica. Em relação ao propranolol, esse aumento do Slc2a4 é diferente do descrito em músculo EDL de ratos submetidos ao bloqueio com propranolol durante o jejum, quando se observou redução (ALVES-WAGNER et al., 2009). Estas diferenças podem se relacionar à presença do diabetes. A associação propranolol/insulina induziu efeitos intermediários aos observados separadamente em cada condição experimental.

O tratamento com insulina aumentou os níveis de ácidos graxos livres, provavelmente gerando um acúmulo de lipídios e seus intermediários no músculo esquelético (SHULMAN, 2000), o que poderia ativar NFKB (ZHANG et al., 2010), reduzindo a expressão de Slc2a4 (SILVA et al., 2005). Como o músculo glicolítico possui menor capacidade de oxidar ácidos graxos (WATRAS, 2004), é possível que o acúmulo lipídico tenha sido maior no músculo EDL, e assim o efeito da insulina seria repressor. Além disso, o uso de propranolol pode ter reduzido o fluxo sanguíneo no músculo esquelético, por reduzir o efeito vasodilatador dos receptores $\beta$ adrenérgicos (HAGSTROM-TOFT et al., 1998), podendo ter gerado uma hipóxia muscular, estimulando HIF1-a (hypoxia inducible factor 1-a), descrito como ativador da transcrição do GLUT4 (SILVA et al., 2005), aumentando então a expressão do Slc2a4. Como o músculo glicolítico possui menor densidade de capilares (LEVY, 2004), é possível que a redução do fluxo 
sanguíneo tenha sido maior nele do que em músculo oxidativo. Isso explicaria as respostas opostas encontradas no EDL.

Ainda, observou-se tanto em sóleo como em EDL, que os animais hipertensos diabéticos tiveram maior expressão de Slc2a4. Estes resultados reforçam a ideia de que o sistema nervoso simpático esteja estimulando a expressão deste gene, já que nesta idade estudada ( 16 semanas) já foi demonstrado um importante aumento da atividade atividade simpática em músculo esquelético (CABASSI et al., 2001), apesar do efeito paradoxal observado com o propranolol no EDL.

Concluídas as análises da regulação da expressão do gene (análise do conteúdo do mRNA Slc2a4), passamos a avaliar a expressão da proteína GLUT4, que nem sempre varia estequiometricamente de acordo com o mRNA.

No músculo oxidativo sóleo, a expressão de GLUT4 foi estimulada pela insulina nos animais normotensos, de acordo com o observado no mRNA. Aumento da expressão do GLUT4 total em tecido adiposo e muscular de ratos diabéticos tratados com insulina já foi relatado na literatura (OKAMOTO et al., 2011; SIVITZ et al., 1992). O propranolol aumentou a proteína GLUT4 somente nos animais hipertensos, isoladamente ou em associação com a insulina, o que corresponde apenas parcialmente ao observado no mRNA. Neste sentido, já foi demonstrado que o bloqueio $\beta$-adrenérgico com propranolol previniu parcialmente a redução da captação periférica de glicose induzida pelo TNF $\alpha$ (LANG, 1993), diminuindo a resistência à insulina (DEIBERT; DEFRONZO, 1980; LANG, 1993). Além disso, a literatura indica que a adrenalina estimula a transcrição e tradução de Tnfa em músculo esquelético de ratos em condições basais (LANG; NYSTROM; FROST, 2008).

Esta bem demonstrado que o Tnfa diminui a expressão do GLUT4 em células adiposas (STEPHENS; PEKALA, 1991), assim como a sinalização da insulina em tecido muscular de humanos (PLOMGAARD et al., 2005), sendo o mesmo expresso em músculo esquelético e cardíaco de humanos e ratos e em cultura de células musculares, e tendo sua expressão aumentada em indivíduos diabéticos e com resistência à insulina (SAGHIZADEH et al., 1996). Portanto, o Tnfa parece ser um importante mediador das alterações de Slc2a4/GLUT4 induzidas pelo diabetes.

Já foi descrito que no diabetes observa-se alta expressão de Tnfa (SAGHIZADEH et al., 1996). Adicionalmente, a atividade $\beta$-adrenérgica estimula a expressão do Tnfa (LANG; 
NYSTROM; FROST, 2008). O Tnfa, além de inibir a expressão gênica do Slc2a4, estimula a degradação de proteínas totais em célula muscular (LI et al., 1998), o que pode induzir diminuição da proteína GLUT4 independentemente da regulação do mRNA Slc2a4. No presente estudo, no sóleo, observou-se alta expressão de Tnfa em todos os grupos, exceto SP e SPI. Nos grupos SP e SPI, o Tnfa foi reduzido, e isto pode ter contribuído para que a proteína aumentasse paralelamente ao aumento do mRNA (quando comparados aos respectivos controles). Nos grupos SS e SI, a proteína não aumentou (conforme o mRNA), o que pode estar relacionado à alta concentração local de Tnfa.

No músculo glicolítico, a variação da proteína GLUT4 seguiu o padrão geral do observado no mRNA. Destaca-se a observação de que os animais hipertensos tratados ou não com insulina ou propranolol tiveram maior conteúdo de GLUT4, reforçando a ideia de que a atividade $\beta$-adrenérgica seja estimuladora da expressão do Slc2a4/GLUT4. Já foi demonstrado que a adrenalina per se induz a translocação do GLUT4, aumentando a captação de glicose em músculo esquelético (HAN; BONEN, 1998). Em conjunto com a presente observação de que alta atividade simpática aumenta o conteúdo celular total de GLUT4, fica claro que a atividade $\beta$ adrenérgica aumenta a utilização de glicose em músculo.

No músculo EDL, a expressão do Tnfa mostrou-se diminuída apenas no grupo WPI, o que poderia explicar os altos níveis de proteína observados neste grupo, e que não diferiram do observado em SPI, apesar do aumento do mRNA neste último.

Embora a densidade de receptores $\beta$-adrenérgicos seja maior em músculo oxidativo (FELL et al., 1985; WILLIAMS; CARON; DANIEL, 1984), já foi demonstrado que o efeito de antagonistas $\beta$-adrenérgicos é maior em fibra glicolítica (WATSON-WRIGHT; WILKINSON, 1986), explicando assim porque os efeitos na expressão do GLUT4 foram mais proeminentes em EDL que em sóleo de animais hipertensos.

Algumas alterações de expressão de mRNA Slc2a4 e da proteína GLUT4, na mesma condição experimental, foram discrepantes, mostrando a ocorrência de alterações póstranscricionais. Conforme já comentado, discrepâncias entre a expressão do mRNA e proteína no tecido muscular esquelético já foram descritas por nosso laboratório, nas quais foram observadas alterações no tamanho da cauda poli(A) do mRNA (ALVES-WAGNER et al., 2009; SERAPHIM et al., 2007). Sabe-se que quanto maior a cauda poli(A) maior a estabilidade do mRNA e maior a sua eficiência de tradução, de tal forma que quantidades semelhantes de mRNA 
podem induzir quantidades bastante distintas de proteína. Por exemplo, no presente estudo, em sóleo de animais Wistar diabéticos, o propranolol diminuiu o mRNA mas não alterou a proteína GLUT4. Esta regulação é exatamente a mesma observada em sóleo de animais não diabético submetidos a bloqueio com propranolol durante evolução de jejum, condição em que foi demonstrado aumento da cauda poli(A) do mRNA Slc2a4, explicando diminuição no conteúdo do mRNA sem alterar a proteína (ALVES-WAGNER et al., 2009).

A análise dos receptores $\beta_{2}$-adrenérgicos, mostrou que em músculo esquelético sóleo os animais hipertensos possuem maior quantidade que os animais normotensos. Apesar de já ter sido demonstrado que os receptores adrenérgicos não se alteram em músculo oxidativo de SHR (ATRAKCHI et al., 1989), é importante ressaltar que esse grupo comparou SHR com WistarKyoto, o que pode explicar a diferença dos resultados apresentados aqui, já que utilizamos Wistar (vs. SHR).

Além disso, um trabalho recente mostrou que o tratamento com propranolol, carvedilol e bisoprolol aumentou o mRNA de receptores adrenérgicos $\beta_{1}$ e $\beta_{2}$ em coração (CHEN et al., 2010). Mostrando que tratamento com $\beta$-bloqueadores pode alterar a quantidade de receptores, como o observado no músculo sóleo (WS vs. WP, comparação não mostrada na figura 13A). Apesar dos resultados encontrados quando o propranolol foi associado à insulina.

No EDL a quantidade de receptores $\beta_{2}$-adrenérgicos não foi alterada, lembrando que músculo glicolítico possui menor expressão de $\beta$-receptores que músculo oxidativo (FELL et al., 1985; WILLIAMS et al., 1984).

Em conjunto, os resultados apresentados evidenciam a participação do sistema $\beta$ adrenérgico na regulação da expressão de Slc2a4/GLUT4 na presença de diabetes mellitus. 


\section{CONCLUSÃO}

O presente estudo mostrou que animais SHR, conhecidos por sua alta atividade simpática, aumentam a expressão de Slc2a4/GLUT4, principalmente em músculo glicolítico. Por outro lado, animais diabéticos Wistar e SHR diminuem a expressão de Slc2a4/GLUT4. O tratamento com propranolol reforçou o efeito estimulador $\beta$-adrenérgico em sóleo de animais normotensos. O Tnfa parece ter participação nas regulações induzidas pelo diabetes, assim como nos efeitos do propranolol sobre a proteína GLUT4 em sóleo de animais SHR. Embora tenha ficado claro que o sistema adrenérgico regule a expressão do gene Slc2a4, os mecanismos transcricionais envolvidos ainda são completamente desconhecidos, merecendo estudos futuros.

Considerando a importância do GLUT4 na homeostasia glicêmica, o presente estudo também sugere que a neuropatia autonômica possa piorar a homeostase glicêmica, por induzir uma maior redução na expressão de GLUT4. Portanto, o desenvolvimento de drogas que possam ativar especificamente a via simpática em músculo esquelético poderia contribuir para melhorar a homeostase glicêmica em indivíduos portadores de diabetes mellitus. 


\section{REFERÊNCIAS*}

AIELLO, E. A.; VILLA-ABRILLE, M. C.; ESCUDERO, E. M.; PORTIANSKY, E. L.; PÉREZ, N. G.; HURTADO, M. C. C.; CINGOLANI, H. E. Myocardial hypertrophy of normotensive Wistar-Kyoto rats. Am. J. Physiol. Heart Circ. Physiol., v. 286, n. 4, p. H1229-H1235, 2004.

ALVES-WAGNER, A. B. T.; FREITAS, H. S.; SOUZA, P. B.; SERAPHIM, P. M.; MORI, R. C. T.; MACHADO, U. F. $\beta$-adrenergic activity preserves GLUT4 protein in glycolytic fibers in fasting. Muscle Nerve, v. 40, n. 5, p. 847-854, 2009.

ATRAKCHI, A.; CARLSEN, R. C.; GRAY, S. D.; MICHEL, A.; HANCE, A. J. Beta-receptor properties in soleus mucles from spontaneously hypertensive rats. Hypertension, v. 14, n.1, p. 54-60, 1989.

BARON, A. D.; BRECHTEL, G.; WALLACE, P.; EDELMAN, S. V. Rates and tissues sites of non-insulin and insulin-mediate glucose uptake in humans. Am. J. Physiol., v. 255, n. 6 Pt 1, p. E769-E774, 1988.

BERGER, J.; BISWAS, C.; VICARIO, P. P.; STROUT, H. V.; SAPERSTEIN, R.; PILCH, P. F. Decreased expression of the insulin-responsive glucose transporter in diabetes and fasting. Nature, v. 340, n. 6228, p. 70-72, 1989.

BERNE, C.; FAGIUS, J.; POLLARE, T.; HJEMDAHL, P. The sympathetic response to euglycaemic hyperinsulinaemia. Evidence from microelectrode nerve recordings in healthy subjects. Diabetologia, v. 35, n. 9, p. 873-879, 1992.

BROWNLEE, M.; AIELLO, L. P.; FRIEDMAN, E.; VINIK, A. I.; NESTO, R. W.; BOULTON, A. J. M. Complications of Diabetes Mellitus. In: LARSEN, P. R.; KRONENBERG, H. M.; MELMED, S.; POLONSKY, K. S. Williams Textbook of Endocrinology. 10th ed. Pensilvania: Elsevier Science, 2002. p.1553, 1558.

CABASSI, A.; VINCI, S.; CANTONI, A. M.; QUARTIERI, F.; MOSCHINI, L.; CAVAZZINI, S.; CAVATORTA, A.; BORGHETTI, A. Sympathetic activation in adipose tissue and skeletal muscle of hypertensive rats. Hypertension, v. 39, n. 2 Pt 2, p. 656-661, 2002.

CABASSI, A.; VINCI, S.; QUARTIERI, F.; MOSCHINI, L.; BORGHETTI, A. Norepinephrine reuptake is impaired in skeletal muscle of hypertensive rats in vivo. Hypertension, v. 37, n. $2 \mathrm{Pt}$ 2, p. 698-702, 2001.

CAMPBELL, I. W.; DOMINICZAK, A. F.; LIVINGSTONE, C.; GOULD, G. W. Analysis of glucose transporter compliment of metabolically important tissues from the Milan hypertensive rat. Biochem. Biophys. Res. Commun., v. 211, n. 3, p. 780-791, 1995.

*De acordo com: ASSOCIAÇÃO BRASILEIRA DE NORMAS TÉCNICAS. NBR 6023: informação e documentação: referências: elaboração. Rio de Janeiro, 2002. 
CAMPS, M.; CASTELlÓ, A.; MUNÕZ, P.; MONFAR, M.; TESTAR, X.; PALACIN, M.; ZORZANO, A. Effect of diabetes and fasting on GLUT4 (muscle/fat) glucose transporter Biochem. J., v. 282, n. Pt 3, p. 765-772, 1992 .

CHEN, W. Q.; CAI, H., ZHANG, C.; JI, X. P.; ZHANG, Y. Is overall blockade superior to selective blockade of adrenergic receptor subtypes in suppressing left ventricular remodeling in spontaneously hypertensive rats? Hypertens. Res., v. 33, n. 10, p. 1071-1081, 2010.

CHROMY, V.; GERGERL, J.; VOZNOCEK, J.; KROMBHOLZOVA, L.; MUSIL, J. Assay for serum free fatty acids by extraction-photometric procedure. Clin. Chim. Acta., v. 80, n. 2, p.
327-332, 1977.

CHIAPPE DE CINGOLANI, G. E.; CALDIZ, C. I. Insulin resistance and GLUT-4 glucose transporter in adipocytes from hypertensive rats. Metabolism., v. 53, n. 3, p. 382-387. 2004.

COOPER, M. E.; BONNET, F.; OLDFIELD, M.; JANDELEIT-DAHM, K. Mechanisms of diabetic vasculopathy: an overview. Am. J. Hypertens., v. 14, n. 5 Pt 1, p. 475-486, 2001.

CRYER, P. E. The metabolic impact of autonomic neuropathy in insulin-dependent Diabetes Mellitus. Arch. Intern. Med., v. 146, n. 11, p. 2127-2129, 1986. DAVIS, L. G.; KUEHL, W. M.; BATTEY, J. F. Basic methods in molecular biology. New
York: Plenum Press, 1994.

DEIBERT, D. C.; DEFRONZO, R. A. Epinephrine-induced insulin resistance in man. J. Clin. Invest., v. 65, n. 3 , p. 717-721, 1980.

DIMITRAKOUDIS, D.; RAMLAL, T.; RASTOGI, S.; VRANIC, M.; KLIP, A. Glycaemia regulates the glucose transporter number in the plasma membrane of rat skeletal muscle. Biochem. J., v. 284, n. Pt 2, p. 341-348, 1992.

DINÇER, Ü. D.; BIDASEE, K. R.; GÜNER, S.; TAY, A.; OZÇELIKAY, A. T.; ALTAN, V. M. The effect of diabetes on expression of beta1-, beta2-, and beta3-adrenoreceptors in rat hearts.
Diabetes, v. 50, n. 2, p. 455-461, 2001 .

ELAYAN, H.; KENNEDY, B.; ZIEGLER, M. G. Propranolol reduces rat dopamine-betahydroxilase activity and catecholamine levels. Eur. J. Pharmacol., v. 212, n. 2-3, p. 259-262,

ESLER, M.; KAYE, D. Sympathetic nervous system activation in essential hypertension, cardiac failure and psychosomatic heart disease. J. Cardiovasc. Pharmacol., v. 35, n. 7, s. 4, p. S1-S7,
2000. 
EVANS, B. A.; PAPAIOANNOU, M.; HAMILTON, S.; SUMMERS, R. J. Alternative splicing generates two isoforms of the beta3-adrenoceptor which are differentially expressed in mouse tissues. Br. J. Pharmacol., v. 127, n. 6, p. 1525-1531, 1999.

FELL, R. D.; LIZZO, F. H.; CERVONI, P.; CRANDALL, D. L.; Effect of contractile activity on rat skeletal muscle beta-adrenoceptor properties. Proc. Soc. Exp. Biol. Med., v. 180, n. 3, p. 527-532, 1985.

FERRARI, P.; WEIDMANN, P. Insulin, insulin sensitivity and hypertension. J. Hypertens., v. 8, n. 6, p. 491-500, 1990.

FLIERS, E.; KREIER, F.; VOSHOL, P. J.; HAVEKES, L. M.; SAUERWEIN, H. P.; KALSBEEK, A.; BUIJS, R. M.; ROMIJN, J. A. White adipose tissue: getting nervous. J. Neuroendocrinology, v. 15, n. 11, p. 1005-1010, 2003. Review.

FREITAS, H. S.; SCHAAN, B. D. A.; SERAPHIM, P. M.; NUNES, M. T.; MACHADO U. F. Acute and short-term insulin-induced molecular adaptations of GLUT2 gene expression in the renal cortex of diabetics rats. Mol. Cell. Endocrinol., v. 237, n. 1-2, p. 49-57, 2005.

FRONTONI, S.; BRACAGLIA, D.; GIGLI, F. Relationship between autonomic dysfunction, insulin resistance and hypertension, in diabetes. Nutr. Metab. Cardiovasc. Dis., v. 15, n. 6, p. 441-449, 2005.

GARFIN, D. E. One-dimensional gel eletrophoresis. Methods Enzimol., v. 182, p. 425-441, 1990.

GERMACK, R.; STARZEC, A. B.; VASSY, R.; PERRET, G. Y. $\beta$-Adrenoceptor subtype expression and function in rat white adipocytes. Br. J. Pharmacol., v. 120, n. 2, p. 201-210, 1997.

GOLDFIEN, A. Adrenal Medulla. In: GREENSPAN, F. S.; GARDNER, D. G. Basic \& Clinical Endocrinology. 6th ed. USA: The McGraw Hill Companies, 2001. p. 405-406.

GOSMANOV, A. R.; WONG, J. A.; THOMASON, D. B. Duality of G protein-coupled mechanisms for beta-adrenergic activation of NKCC activity in skeletal muscle. Am. J. Physiol. Cell. Physiol., v. 283, n. 4, p. C1025-C1032, 2002.

GUYNET, P. G. The sympathetic control of blood pressure. Nat. Rev. Neurosci., v. 7, n. 5, p. 335-346, 2006.

HAGSTRÖM-TOFT, E.; ENOKSSON, S.; MOBERG, E.; BOLINDER, J.; ARNER, P. betaAdrenergic regulation of lipolysis and blood flow in human skeletal muscle in vivo. Am. J. Physiol., v. 275, n. 6 Pt 1, p. E909-E916, 1998.

HAN, X. X.; BONEN, A. Epinephrine translocates GLUT-4 but inhibits insulin-stimulated glucose transport in rat muscle. Am. J. Physiol., v. 274, n. 4 Pt 1, p. E700-E707, 1998. 
HUPFELD, C. J.; DALLE, S.; OLEFSKY, J. L. Beta -Arrestin 1 down-regulation after insulin treatment is associated with supersensitization of beta 2 adrenergic receptor Galpha s signaling in 3T3-L1 adipocytes. Proc. Natl. Acad. Sci. USA., v. 100, n. 1, p. 161-166, 2003.

HUTCHINSON, D. S.; BENGTSSON, T.; EVANS, B. A.; SUMMERS, R. J. Mouse beta 3aand beta 3 b-adrenoceptors expressed in Chinese hamster ovary cells display identical pharmacology but utilize distinct signaling pathways. Br. J. Pharmacol., v. 135, n. 8, p. 19031914, 2002.

JAMES, D. E.; JENKINS, A. B.; KRAEGEN, E. W. Heterogeneity of insulin action in individual muscles in vivo: euglycemic clamp studies in rats. Am. J. Physiol., v. 248, n. 5 Pt 1, p. E567-E574, 1985.

JOINT NATIONAL COMMITTEE ON PREVENTION, DETECTION, EVALUATION, AND TREATMENT OF HIGH BLOOD PRESSURE. The seventh report of the Joint National Committee on Prevention, Detection, Evaluation and Treatment of High Blood Pressure (JNC 7). National Institutes of Health Publication, No 04-5230. 2004.

KATAYAMA, S.; INABA, M.; MARUNO, Y.; MORITA, T.; AWATA, T.; OKA, Y. Glucose intolerance in spontaneously hypertensive and Wistar-Kyoto rats: enhanced gene expression and synthesis of skeletal muscle glucose transporter 4. Hypertens. Res., v. 20, n. 4, p. 279-286, 1997.

KERN, M.; WELLS, J. A.; STEPHENS, J. M.; ELTON, C. W.; FRIEDMAN, J. E.; TAPSCOTT, E. B.; PEKALA, P. H.; DOHM, G. L. Insulin responsiveness in skeletal muscle is determined by glucose transporter (GLUT4) protein level. Biochem. J., v. 270, n. 2, p. 397-400, 1990.

KIM, Y. S.; SAINZ, R. D.; MOLENAAR, P.; SUMMERS, R. J. Characterization of $\beta_{1^{-}}$and $\beta_{2^{-}}$ adrenoceptors in rat skeletal muscles. Biochem. Pharmacol., v. 42, n. 9, p. 1783-1789, 1991.

KIMURA, H.; MIYAMOTO, A.; OHSHIKA, H. Down regulation of beta-adrenoceptors and loss of Gs alpha subunits levels in ventricular myocardium of rats treated with isoproterenol. Life Sci., v. 53, n. 10, p. PL171-PL176, 1993.

KRSSAK, M.; FALK PETERSEN, K.; DRESNER, A.; DIPIETRO, L.; VOGEL, S. M.; ROTHMAN, D. L.; RODEN, M.; SHULMAN, G. I. Intramyocellular lipid concentrations are correlated with insulin sensitivity in humans: a $1 \mathrm{H}$ NMR spectroscopy study. Diabetologia, v. 42, n. 1, p. 113-116, 1999.

KUBOTA, T.; YAMADA, T. Alterations in vascular sensitivity to vasoactive agents after discontinuation of propranolol in SHR. Hypertension., v. 6, n. 2 Pt 1, p. 249-254, 1984.

LAFONTAN, M.; BERLAN, M. Fat cell adrenergic receptors and the control of white and brown fat cell function. J. Lipid. Res., v. 34, n. 7, p. 1057-1091, 1993. Review. 
LANG, C. H. Beta-adrenergic blockade attenuates insulin resistance induced by tumor necrosis factor. Am. J. Physiol., v. 264, n. 5 Pt 2, p. R984-R991,1993.

LANG, C. H.; NYSTROM, G.; FROST, R. A. Beta-adrenergic blockage exacerbates sepsisinduced changes in tumor necrosis factor alpha and interleukin-6 in skeletal muscle and is associated with impaired translation initiation. J. Trauma, v. 64, n. 2, p. 477-486, 2008.

LENZEN, S. The mechanisms of alloxan- and streptozotocin-induced diabetes. Diabetologia, v. 51, p. 216-226, 2008. Review.

LEVY, M. N. Circulações especiais. In: BERNE, R. M.; LEVY, M. N.; KOEPPEN, B. M.; STANTON, B. A. Fisiologia. $5^{\text {a }}$ ed. Rio de Janeiro: Elsevier, 2004. p. 446.

LI, Y. P.; SCHWARTZ, R. J.; WADDELL, I. D.; HOLLOWAY, B. R.; REID, M. B. Skeletal muscle myocytes undergo protein loss and reactive oxygen-mediated NF- $\kappa B$ activation in response to tumor necrosis factor alpha. FASEB., v. 12, n. 10, p. 871-880, 1998.

LIRA, E. C.; GRAÇA, F. A.; GONÇALVES, D. A. P.; ZANON, N. M.; BAVIERA, A. M.; STRINDBERG, L.; LONNROTH, P.; MIGLIORINI, R. H.; KETTELHUT, I. C.; NAVEGANTE, L. C. C. Cyclic adenosine monophosphate-phosphodiesterase inhibitors reduce skeletal muscle protein catabolism in septic rats. Shock., v. 27, n. 6, p. 687-694, 2007.

LOWRY, O. H.; ROSEMBROUGH, N. J.; FARR, A. L.; RANDAL, R. J. Protein measurement with the folin phenol reagent. J. Biol. Chem., v. 193, n. 1, p. 265-275, 1951.

LYNCH, G. S.; RYALL, J. G. Role of beta-adrenoceptor signaling in skeletal muscle: implications for muscle wasting and disease. Physiol. Rev., v. 88, n. 2, p. 729-767, 2008. Review.

MACHADO, U. F.; SHIMIZY, Y.; SAITO, M. Decreased glucose transporter (GLUT4) content in insulin-sensitive tissues of obese aurothioglucose- and monosodium glutamate-treated mice. Horm. Metab. Res., v. 25, n. 9, p. 462-465, 1993.

MASHARANI, U.; KARAM, J. H. Pancreatic Hormones \& Diabetes Mellitus. In: GREENSPAN, F. S.; GARDNER, D. G. Basic \& Clinical Endocrinology. 6th ed. USA: The McGraw Hill Companies, 2001. p. 633.

MORA, S.; PESSIN, J. E. The MEF2A isoform is required for striated muscle-specific expression of the insulin-responsive GLUT4 glucose transporter. J. Biol. Chem., v. 275, n. 21, p. 16323-16328, 2000.

NAPOLI, R.; HIRSHMAN, M. F.; HORTON, E. S. Mechanisms and time course of impaired skeletal muscle glucose transport activity in streptozocin diabetic rats. J. Clin. Invest., v. 96, n. 1, p. 427-437, 1995. 
NIETO-VAZQUEZ, I.; FERNANDEZ-VELEDO, S.; KRAMER, D. K.; VILA-BEDMAR, R.; GARCIA-GUERRA, L.; LORENZO, M. Insulin resistance associated to obesity: the link TNFalpha. Arch Physiol Biochem., v. 114, n. 3, p. 183-194, 2008. Review.

NONOGAKI, K. New insights into sympathetic regulation of glucose and fat metabolism. Diabetologia, v. 43, n. 5, p. 533-549, 2000.

OKAMOTO, K.; AOKI, K. Development of a strain of spontaneously hypertensive rats. Jpn. Circ. J., v. 27, p. 282-293, 1963.

OKAMOTO, M. M.; ANHÊ, G. F.; SABINO-SILVA, R.; MARQUES, M. F. S. F.; FREITAS, H. S.; MORI, R. C. T.; MELO, K. F. S.; MACHADO, U. F. Intensive insulin treatment induces insulin resistance in diabetic rats by impairing glucose metabolism-related mechanisms in muscle and liver. J. Endocrinol., v. 211, n. 1, p. 55-64, 2011.

PAN, D. A.; LILLIOJA, S.; KRIKETOS, A. D.; MILNER, M. R.; BAUR, L. A.; BOGARDUS, C.; JENKINS, A. B.; STORLIEN, L. H. Skeletal muscle triglyceride levels are inversely related to insulin action. Diabetes, v. 46, n. 6, p. 983-988, 1997.

PATERnOSTRO, G.; ClARKE, K.; HEATH, J.; SEYMOUR, A. M.; RADDA, G. K. Decreased GLUT-4 mRNA content and insulin-sensitive deoxyglucose uptake show insulin resistance in the hypertensive rat heart. Cardiovasc. Res., v. 30, n. 2, p. 205-211, 1995.

PERSEGHIN, G.; GHOSH, S.; GEROW, K.; SHULMAN, G. I. Metabolic defects in lean nondiabetic offspring of NIDDM parents: a cross-sectional study. Diabetes, v. 46, n. 6, p. 10011009, 1997.

PLOMGAARD, P.; BOUZAKRI, K.; KROGH-MADSEN, R.; MITTENDORFER, B.; ZIERATH, J. R.; PEDERSEN, B. K. Tumor necrosis factor-alpha induces skeletal muscle insulin resistance in healthy human subjects via inhibition on Akt substrate 160 phosphorylation. Diabetes, v. 54, n. 10, p. 2939-2945, 2005.

RATTIGAN, S.; APPLEBY, G. J.; EDWARDS, S. J.; MCKINSTRY, W. J.; COLQUHOUN, E. Q.; CLARK, M. G.; RICHTER, E. A. Alpha-adrenergic receptors in rat skeletal muscle. Biochem. Biophys. Res. Commun., v. 136, n. 3, p. 1071-1077, 1986.

REAVEN, G. M.; CHANG, H.; HOFFMAN, B. B.; AZHAR, S. Resistance to insulin-stimulated glucose uptake in adipocytes isolated from spontaneously hypertensive rats. Diabetes, v. $38, \mathrm{n}$. 9, p. 1155-1160, 1989.

RICHARDSON, J. M.; BALON, T. W.; TREADWAY, J. L.; PESSIN, J. E. Differential regulation of glucose transporter activity and expression in red and white skeletal muscle. $\mathbf{J}$. Biol. Chem., v. 266, n.19, p. 12690-12694, 1991. 
RODRÍGUEZ, A.; CATALÁN, V.; BECERRIL, S.; GIL, M. J.; MUQUETA, C.; GÓMEZAMBROSI, J.; FRÜHBECK, G. Impaired adiponectin-AMPK signalling in insulin-sensitive tissues of hypertensive rats. Life Sci., v. 83, n. 15-16, p. 540-549, 2008.

SABINO-SILVA, R.; ALVES-WAGNER, A. B. T.; BURGI, K.; OKAMOTO, M. M.; ALVES, A. S.; LIMA, G. A.; FREITAS, H. S.; ANTUNES, V. R.; MACHADO, U. F. SGLT1 protein expression in plasma membrane of acinar cells correlates with the sympathetic outflow to salivary glands in diabetic and hypertensive rats. Am. J. Physiol. Endocrinol. Metab., v. 299, n. 6, p. E1028-E1037, 2010.

SAGHIZADEH, M.; ONG, J. M.; GARVEY, W. T.; HENRY, R. R.; KERN, P. A. The expression of TNF $\alpha$ by human muscle. Relationship to insulin resistance. J. Clin. Invest., v. 97 ,
n. 4, p. 1111-1116, 1996.

SALANS, L. B.; ZARNOWSKI, M. J.; SEGAL, R. Effect of insulin upon the cellular character of rat adipose tissue. J. Lipid. Res., v. 13, n. 5, p. 616-623, 1972.

SAMUEL, V. T.; PETERSEN, K. F.; SHULMAN, G. I. Lipid-induced insulin resistance: unravelling the mechanism. Lancet, v. 375, n. 9733, p. 2267-2277, 2010. Review.

SCARPINI, E.; BIANCHI, R.; MOGGIO, M.; SCIACCO, M.; FIORI, M. G.; SCARLATO, G. Decrease of nerve $\mathrm{Na}+, \mathrm{K}(+)$-ATPase activity in the pathogenesis of human diabetic neuropathy. J. Neurol. Sci., v. 120, n. 2, p. 159-167, 1993.

SERAPHIM, P. M.; NUNES, M. T.; GIANNOCCO, G.; MACHADO, U. F. Age related obesityinduced shortening of GLUT4 mRNA poly(A) tail length in rat gastrocnemius skeletal muscle. Mol. Cell. Endocrinol., v. 276, n. 1-2, p. 80-87, 2007.

SHEPHERD, P. R.; KAHN, B. B. Glucose transporters and insulin action: implications for insulin resistance and Diabetes Mellitus. N. Engl. J. Med., v. 341, n. 4, p. 248-257, 1999.

SHULMAN, G. I. Cellular mechanisms of insulin resistance. J. Clin. Invest., v. 106, n. 2, p. 171-176, 2000. Review.

SILVA, J. L.; GIANNOCCO, G.; FURUYA, D. T.; LIMA, G. A.; MORAES, P. A.; NACHEF, S.; BORDIN, S.; BRITTO, L. R.; NUNES, M. T.; MACHADO U. F. NF-kappaB, MEF2A, MEF2D and HIF-a involvement on insulin- and contraction-induced regulation of GLUT4 gene expression in soleus muscle. Mol. Cell. Endocrinol., v. 240, n. 1-2, p. 82-93, 2005.

SIVITZ, W. I.; DESAUTEL, S. L.; KAYANO, T.; BELL, G. I.; PESSIN, J. E. Regulation of glucose transporter messenger RNA in insulin-deficient states. Nature, v. 340, n. 6228, p. 72-74,
1989.

SIVITZ, W. I.; DESAUTEL, S. L.; LEE, E. C.; PESSIN, J. E. Time-dependent regulation of rat adipose tissue glucose transporter (GLUT4) mRNA and protein by insulin in streptozocindiabetic and normal rats. Metabolism., v. 41, n. 11, p. 1267-1272, 1992. 
SMITS, J. F.; STRUYKER-BOUDIER, H. A. The mechanisms of antihypertensive action of beta-adrenergic receptor blocking drugs. Clin. Exp. Hypertens. A., v. 4, n. 1-2, p. 71-86, 1982.

STEPHENS, J. M.; PEKALA, P. H. Transcriptional repression of the GLUT4 and C/EBP genes in 3T3-L1 adipocytes by tumor necrosis factor-alpha. J. Biol. Chem., v. 266, n. 32, p. 2182921845, 1991.

STRALFORS, P.; BJORGELL, P.; BELFRAGE, P. Hormonal regulation of hormone-sensitive lipase in intact adipocytes: Identification of phosphorylated sites and effects on the phosphorylation by lipolytic hormones and insulin. Proc. Natl. Acad. Sci. USA., v. 81, n. 11, p. 3317-3321, 1984.

SZTALRYD, C.; KRAEMER, F. B. Regulation of hormone-sensitive lipase in streptozotocininduced diabetic rats. Metabolism, v. 44, n. 11, p. 1391-1396, 1995.

TAKEDA, K.; BUÑAG, R. D. Chronic propranolol treatment inhibits sympathetic nerve activity and keeps blood pressure from rising in spontaneously hypertensive rats. Hypertension, v. 2, n. 2, p. $228-235,1980$.

TAKEDA, K.; NAKAGAWA, Y.; HASHIMOTO, T.; SAKURAI, H.; IMAI, S. Effects of several beta-blocking agents on the development of hypertension in spontaneously hypertensive rats. Jpn. J. Pharmacol., v. 29, n. 2, p. 171-178, 1979.

TENTOLOURIS, N.; ARGYRAKOPOULOU, G.; KATSILAMBROS, N. Perturbed autonomic nervous system function in metabolic syndrome. Neuromol. Med., v. 10, n. 3, p. 169-178, 2008. Review.

THORENS, B.; CHARRON, M. J.; LODISH, H. F. Molecular physiology of glucose transporter. Diabetes Care, v. 13, n. 3, p. 209-218, 1990. Review.

TIMMONS, T. M.; DUNBAR, B. Protein blotting and immunodetection. Methods Enzymol., v. 182, p. 679-688, 1990.

TOWBIN, H.; STAEHELIN, T.; GORDON, J. Eletrophoretic transfer of proteins from polyacrilamide gels to nitrocellulose sheets: procedure and some implications. Proc. Natl. Acad. Sci. USA., v. 76, n. 9, p. 4350-4354, 1979.

VINIK, A. I.; MASER, R. E.; MITCHELL, B. D.; FREEMAN, R. Diabetic Autonomic Neuropathy. Diabetes Care, v. 26, n. 5, p. 1553-1579, 2003.

WATRAS, J. Fisiologia do músculo esquelético. In: BERNE, R. M.; LEVY, M. N.; KOEPPEN,

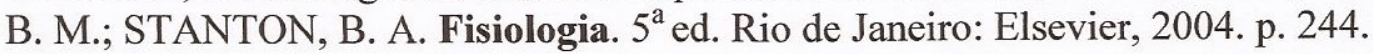

WATSON-WRIGHT, M. W.; WILKINSON, M. The muscle slice - a new preparation for the characterization of beta-adrenergic binding in fast- and slow-twich skeletal muscle. Muscle Nerve, v. 9, n. 5, p. 416-422,1986. 
WHITE, B. A. Regulação hormonal do metabolism energético. In: KOEPPEN, B. M.; STANTON, B. A. Berne \& Levy Fisiologia. $6^{\text {a }}$ ed. Rio de Janeiro: Elsevier, 2009. p. 690-691.

WILLIAMS, R. S.; CARON, M. G.; DANIEL, K. Skeletal muscle beta-adrenergic receptors: variations due to fiber type and training. Am. J. Physiol., v. 246, n. 2 Pt 1, p. E160-E167, 1984.

WILLIS Jr, W.D. O Sistema Nervoso. In: BERNE, R. M.; LEVY, M. N.; KOEPPEN, B. M.; STANTON, B. A. Fisiologia. $5^{\text {a }}$ ed. Rio de Janeiro: Elsevier, 2004. p. 220.

XIAO, R. P.; AVDONIN, P.; ZHOU, Y. Y.; CHENG, H.; AKHTER, S. A.; ESCHENHAGEN, T.; LEFKOWITZ, R. J.; KOCH, W. J.; LAKATTA, E. G. Coupling of beta2-adrenoceptor to Gi proteins and its physiological relevance in murine cardiac myocytes. Circ. Res., v. 84, n. 1, p.
$43-52,1999$.

YOSHIDA, T.; NISHIOKA, H.; NAKAMURA, Y.; KONDO, M. Reduced noradrenaline turnover in streptozotocin-induced diabetic rats. Diabetologia, v. 28, n. 9, p. 692-696, 1985.

ZECCHIN, H. G.; BEZERRA, R. M.; CARVALHEIRA, J. B.; CARVALHO-FILHO, M. A.; METZE, K.; FRANCHINI, K. G.; SAAD, M. J. Insulin signaling pathways in aorta and muscle from two animal models of insulin resistance-the obese middle-aged and the spontaneously hypertensive rats. Diabetologia., v. 46, n. 4, p. 479-491, 2003.

ZHANG, J.; WU, W.; LI, D.; GUO, Y.; DING, H. Overactivation of NF- $\kappa$ B impairs insulin sensitivity and mediates palmitate-induced insulin resistance in $\mathrm{C} 2 \mathrm{C} 12$ skeletal muscle cells. Endocrine., v. 37, n. 1, p. 157-166, 2010. 